\title{
Excitation of GABAergic Neurons in the Bed Nucleus of the Stria Terminalis Triggers Immediate Transition from Non-Rapid Eye Movement Sleep to Wakefulness in Mice
}

\author{
[DShota Kodani, ${ }^{1}$ (EShingo Soya, ${ }^{1,2,3}$ and $\odot T a k e s h i$ Sakurai ${ }^{1,2,3,4}$ \\ ${ }^{1}$ Department of Molecular Neuroscience and Integrative Physiology, Faculty of Medicine, Kanazawa University, Kanazawa, Ishikawa 920-8640, Japan, \\ ${ }^{2}$ Faculty of Medicine, University of Tsukuba, Tsukuba, Ibaraki, 305-8575, Japan, ${ }^{3}$ International Institute for Integrative Sleep Medicine (WPI-IIIS), \\ University of Tsukuba, Tsukuba, Ibaraki 305-8575, Japan, and ${ }^{4}$ Life Science Center for Tsukuba Advanced Research Alliance, University of Tsukuba, \\ Tsukuba, Ibaraki 305-8575, Japan
}

Emotionally salient situations usually trigger arousal along with autonomic and neuroendocrine reactions. To determine whether the extended amygdala plays a role in sleep-wakefulness regulation, we examined the effects of optogenetic and pharmacogenetic excitation of GABAergic neurons in the bed nucleus of the stria terminalis (GABA ${ }^{\text {BNST }}$ neurons). Acute optogenetic excitation of these cells during nonrapid eye movement (NREM) sleep resulted in an immediate state transition to wakefulness, whereas stimulation during REM sleep showed no effect on sleep-wakefulness states in male mice. An anterograde tracing study suggested GABA ${ }^{\text {BNST }}$ neurons send axonal projections to several brain regions implicated in arousal, including the preoptic area, lateral hypothalamus, periaqueductal gray, deep mesencephalic nucleus, and parabrachial nucleus. A dual orexin receptor antagonist, DORA-22, did not affect the optogenetic transition from NREM sleep to wakefulness. Chemogenetic excitation of GABA ${ }^{\text {BNST }}$ neurons evoked a sustained wakefulness state, but this arousal effect was markedly attenuated by DORA-22. These observations suggest that GABA ${ }^{\text {BNST }}$ neurons play an important role in transition from NREM sleep to wakefulness without the function of orexin neurons, but prolonged excitation of these cells mobilizes the orexin system to sustain wakefulness.

Key words: emotion; sleep; wakefulness

Significance Statement

We examined the role of the bed nucleus of the stria terminalis (BNST) in the regulation of wakefulness. Optogenetic excitation of GABAergic neurons in the BNST (GABA ${ }^{\text {BNST }}$ neurons) during nonrapid eye movement (NREM) sleep in mice resulted in immediate transition to a wakefulness state without function of orexins. Prolonged excitation of GABA ${ }^{\text {BNST }}$ neurons by a chemogenetic method evoked a longer-lasting, sustained wakefulness state, which was abolished by preadministration of a dual orexin receptor antagonist, DORA-22. This study revealed a role of the BNST GABAergic system in sleep-wakefulness control, especially in shifting animals' behavioral states from NREM sleep to wakefulness, and provides an important insight into the pathophysiology of insomnia and the role of orexin in arousal regulation.

\section{Introduction}

Animals shift their sleep-wakefulness state according to their internal state and the external environment by using three major

Received Jan. 26, 2017; revised June 5, 2017; accepted June 12, 2017

Author contributions: S.K. and T.S. designed research; S.K., S.S., and T.S. performed research; S.K. and T.S. analyzed data; S.K., S.S., and T.S. wrote the paper.

This work was supported by the Merck Investigator Studies Program (Grant 54843), a KAKENHI Grant-in-Aid for Scientific Research on Innovative Areas (Adaptive Circuit Shift Grant JP15H01425 to T.S.), the Japan Society for the Promotion of Science (KAKENHI Grant-in-Aid for Scientific Research B JP 15H03122, KAKENHI Grant-in-Aid for Exploratory Research JP 15K12768, and KAKENHI Grant-in-Aid for Scientific Research on Innovative Areas 16H06401 to T.S.). We thank Dr. Kenji Sakimura for providing Gad67-Cre mice, Dr. Karl Deisseroth for providing PAAV-EF1adouble floxed-hChR2(H134R)-EYFP-WPRE-HGHpA and pAAV-EF1a-double floxed-EYFP-WPRE-HGHpA mice, Dr. Bryan influential elements: homeostatic, circadian, and allostatic factors. Among them, allostatic factors include the nutritional state and external environment, which trigger emotion (Saper et al., 2010). For example, stressful and emotionally salient situations

Roth for providing pAAV-EF1a-DI0-hM3D(Gq)-mCherry, the Penn Vector Core for providing pAAV2-rh10, Dr. Takash Maejima and Ms. Yuki Saito for excellent technical assistance, Dr. Michihiro Mieda for continuous support, and Dr. Wendy Gray for reading the manuscript.

This study was partly funded by Merck Sharp and Dohme Corp.

Correspondence should be addressed to Dr. Takeshi Sakurai, Faculty of Medicine, University of Tsukuba, Tsukuba, Ibaraki305-857, Japan. E-mail: sakurai.takeshi.gf@u.tsukuba.ac.jp. DOI:10.1523/JNEUROSCI.0245-17.2017

Copyright $\odot 2017$ the authors $\quad 0270-6474 / 17 / 377164-13 \$ 15.00 / 0$ 
such as encountering predators, adapting to novel situations, or expecting a reward require animals to shift their behavior to a vigilant state, along with alteration of their physiological condition through modulation of autonomic and endocrine functions (Winsky-Sommerer et al., 2004; Cano et al., 2008).

The bed nucleus of the stria terminalis (BNST) is a constituent of the extended amygdala that is generally considered to play an important role in stress response, fear, and anxiety (Davis et al., 2010; Lebow and Chen, 2016). Through projections to various brain regions, including relay nuclei of the autonomic nervous system, hypothalamic regions, and the central nucleus of the amygdala, the BNST plays a major role in endocrine and autonomic reactions in response to emotionally salient stimuli, along with behavioral expression of anxiety and fear. Animal experiments have suggested that expression of anxiety-like behaviors requires the function of the BNST, whereas excitation of the BNST resulted in anxiety-like behaviors (Fendt et al., 2003; Sullivan et al., 2004; Kalin et al., 2005; Straube et al., 2007). These observations suggest the possibility that the BNST also plays an important role in increasing vigilance level and arousal in response to environmental factors associated with stress and danger.

In humans, some psychiatric conditions that are characterized by increased fear and anxiety, such as anxiety disorders, compulsive behavior disorders, and posttraumatic stress disorder and depression, are usually accompanied by sleep disorders such as insomnia or nightmares (Khazaie et al., 2016). From the viewpoint of sleep-wakefulness control, investigating the function of the BNST will potentially provide key information to understanding the pathophysiology of insomnia associated with these stress-related psychiatric disorders as well as primary insomnia, which sometimes results from anxiety due to being unable to sleep (somniphobia or hypnophobia).

The BNST is a heterogeneous area with different physiological functions, diverse input-output architecture, and distinct gene expression patterns of its subnuclei (Lebow and Chen, 2016). However, GAD67 (also referred to as GAD1) is predominantly expressed in the entire BNST, suggesting that GABAergic neurons are the major population of the BNST and may have a pivotal role in physiological functions (Kudo et al., 2012; Lebow and Chen, 2016). In this study, we aimed at revealing the function of the major neuronal subtype, GAD67-expressing GABAergic neurons in the BNST (GABA ${ }^{\text {BNST }}$ neurons) in sleep-wakefulness regulation.

We found that acute optogenetic excitation of GABA ${ }^{\text {BNST }}$ neurons during nonrapid eye movement (NREM) sleep in mice resulted in immediate transition to a wakefulness state without the function of orexins, neuropeptides that play a highly important role in maintenance of wakefulness. Notably, stimulation of $\mathrm{GABA}^{\mathrm{BNST}}$ neurons during REM sleep did not show any effects on sleep-wakefulness states.

We also found that longer excitation of GABA ${ }^{\mathrm{BNST}}$ neurons by a chemogenetic method evoked a longer-lasting, sustained wakefulness state, which was decreased by preadministration of a dual orexin receptor antagonist, DORA-22.

This study adds new knowledge about the function of the BNST GABAergic system in sleep-wakefulness control, especially in shifting animals' behavioral states from NREM sleep to wakefulness, and provides an important insight into the pathophysiology of insomnia and the role of orexin in arousal regulation.

\section{Materials and Methods}

Animals. All experimental procedures were approved by the Animal Experimental and Use Committee of Kanazawa University (AP-122500) and were in accordance with U.S. National Institutes of Health guide- lines. All mice used in this study were backcrossed to C57B6/J mice (http://jaxmice.jax.org/strain/013636.html) $>10$ times, male, $\sim 12-20$ weeks of age, and had a body weight of $\sim 25-32 \mathrm{~g}$ at the time of surgery. We used heterozygous GAD67-Cre mice in which the Cre recombinase gene was knocked-in in the GAD67 allele (Wu et al., 2011). The mice were maintained at $22^{\circ} \mathrm{C}$ with a strict $12 \mathrm{~h}$ light/dark cycle (light on at 8:45 local time) and had ad libitum access to food and water.

Plasmids. We used $p A A V$-EF1a-DIO- $h M 3 D(G q)$-mCherry (provided by Dr. Bryan Roth), pAAV-EF1a-DIO-hChR2(H134R)-EYFP-WPREHGHPA (provided by Dr. Karl Deisseroth), pAAV-EF1a-DIO-EYFPWPRE-HGHpA (plasmid \#20296; Addgene), pHelper (Stratagene), and pAAV2-rh10 (provided by the Penn Vector Core).

Virus production. The $\mathrm{AAV}_{10}$ virus vectors were produced using a triple transfection, helper-free method and purified as described previously (Mieda et al., 2015). The titers of recombinant AAV vectors (genomic copies/milliliter) were as follows; $A A V_{10-} E F 1 \alpha-D I O-h M 3 D q-$ $m$ Cherry, $1.16 \times 10^{13} ; A A V_{10}-E F 1 \alpha$-DIO-ChR2-EYFP, $3.70 \times 10^{13}$; and $A A V_{10}-E F 1 \alpha$-DIO-EYFP, $5.82 \times 10^{13}$

Surgery. The GAD67-Cre mice were deeply anesthetized with sodium pentobarbital $(64.8 \mathrm{mg} / \mathrm{kg})$. AAV vectors $(0.10 \sim 0.25 \mu \mathrm{l})$ were stereotactically injected into the BNST bilaterally (anteroposterior, $+0.2 \mathrm{~mm}$; mediolateral, $\pm 1.0 \mathrm{~mm}$; dorsoventral, $-4.2 \mathrm{~mm}$ from the bregma). For optogenetic studies, optic fibers were bilaterally implanted in the BNST $\left( \pm 30^{\circ}\right.$ angle to sagittal line; anteroposterior, $+0.2 \mathrm{~mm}$; mediolateral, $\pm 1.1 \mathrm{~mm}$; dorsoventral, $-3.7 \mathrm{~mm}$ from the bregma) and fixed with photocurable resin. For implantation of EEG/EMG electrodes, four holes were drilled at $\pm 2 \mathrm{~mm}$ anterior and $\pm 2 \mathrm{~mm}$ lateral to the bregma. Stainless wires (Cooner) for monitoring EMG were inserted bilaterally into the neck muscles and connected to the EEG/EMG electrodes. The electrodes were fixed rigidly with dental cement. After a recovery period of at least 1 week in home cages, mice were subjected to experiments.

Drugs. Clozapine-N-oxide (CNO, catalog \#34233-69-7; Sigma-Aldrich) was dissolved in saline $(0.5 \mathrm{mg} / \mathrm{ml})$. DORA-22 $(((2 \mathrm{R}, 5 \mathrm{R})-5$ - ((5-fluoropyridin-2-yl) oxymethyl)-2-methylpiperidin-1-yl)-(5-fluoro-2-pyrimidin-2ylphenyl) methanone) (Gotter et al., 2013) was provided by Merck Sharp \& Dohme and was dissolved in 20\% vitamin E TPGS (D- $\alpha$ tocopheryl polyethylene glycol 1000 succinate, $6 \mathrm{mg} / \mathrm{ml}$, catalog \#9002-96-4; Sigma-Aldrich).

Oral administration. A $22 \mathrm{G}$ ball tip needle was passed gently through the mouth and pharynx into the esophagus of mice. DORA-22 $(30 \mathrm{mg} / \mathrm{kg}$, freshly prepared in $20 \%$ vitamin E TPGS) or vehicle was then administered slowly. Oral administration of DORA-22 or $20 \%$ vitamin E TPGS was done $30 \mathrm{~min}$ before intraperitoneal $\mathrm{CNO} /$ saline administration.

Sleep recording. The EEG and EMG signals were amplified through an amplifier (AB-611J; Nihon Koden). The EEG signals were filtered at 0.5 $\mathrm{Hz}$ (low) and $100 \mathrm{~Hz}$ (high). The EMG signals were filtered at $15 \mathrm{~Hz}$ (low) and $300 \mathrm{~Hz}$ (high). The signals were recorded digitally in a computer using EEG/EMG recording software (Vital Recorder; Kissei Comtec).

Designer receptors exclusively activated by designer drugs (DREADD). After specifically expressing $\mathrm{hM}_{3} \mathrm{Dq}$ in $\mathrm{GABA}^{\mathrm{BNST}}$ neurons by AAVmediated gene transfer, $\mathrm{CNO}(5.0 \mathrm{mg} / \mathrm{kg})$ or saline was randomly administered intraperitoneally to mice with a $30 \mathrm{G}$ needle at ZT4.0. EEG and EMG recordings were initiated just after drug administration and continued for $5 \mathrm{~h}$. Each mouse was administered with CNO or saline with an interval for at least $3 \mathrm{~d}$ and experiments were conducted using a crossover method to avoid the repeat effects. Experimenters were blind to the drugs (CNO or saline) administered. In the DORA-22 experiment, DORA-22 or vehicle was orally administered $30 \mathrm{~min}$ before intraperitoneal CNO or saline injection and all drug combinations were applied to each mouse at $3 \mathrm{~d}$ intervals. EEG/EMG were scored visually into $16 \mathrm{~s}$ epochs of wakefulness, REM, and non-REM sleep according to standard criteria of rodent sleep (Radulovacki et al., 1984).

Optogenetics. Optical cables were connected to implanted optic fibers to deliver $473 \mathrm{~nm}$ laser stimulation at least $1 \mathrm{~h}$ before experiments. Cables were wrapped with thin aluminum sheets to reduce light leakage. Laser intensity was calibrated to $\sim 10-12 \mathrm{~mW} / \mathrm{mm}^{2}$ for each experiment. During each experiment, EEG/EMG were monitored visually. Pulses of 473 $\mathrm{nm}$ light with $10 \mathrm{~ms}$ width and $20 \mathrm{~Hz}$ frequency were applied during NREM or REM sleep for $20 \mathrm{~s}$. Photostimulation was applied during 
NREM sleep when it continued for $40 \mathrm{~s}$ or longer and during REM sleep when it lasted $30 \mathrm{~s}$ or longer.

c-Fos immunostaining. Orexin, tyrosine hydroxylase (TH), histidine decarboxylase (HDC), tryptophan hydroxylase (TPH), and c-Fos signals were counted by observers who were blind to the drug administered (CNO or saline) and c-Fos/orexin-, c-Fos/TH-, c-Fos/HDC-, and c-Fos/ TPH-positive neurons were counted.

In situ hybridization. In situ hybridization histochemistry was performed as described previously (Mieda et al., 2011). In brief, floating brain sections $(30 \mu \mathrm{m})$ were treated with $4 \%$ paraformaldehyde and $0.3 \%$ Triton X-100 sequentially. After rinsing with PBS three times, the sections were incubated in proteinase $\mathrm{K}\left(2 \mu \mathrm{g} / \mathrm{ml}, 30 \mathrm{~min}\right.$, at $\left.37^{\circ} \mathrm{C}\right)$ followed by $0.75 \%$ glycine ( $15 \mathrm{~min}, 2$ times), and treated with $4 \%$ PFA. After rinsing with PBS, the sections were treated with $0.5 \%$ acetic anhydrate for acetylation. After incubation with hybridization buffer at $60^{\circ} \mathrm{C}$, sections were incubated with digoxin-conjugated antisense GAD67 RNA probes for $16 \mathrm{~h}$ at $60^{\circ} \mathrm{C}$. Sections were washed in $2 \times$ standard saline citrate (SSC) with $50 \%$ formamide $/ 0.1 \% \mathrm{~N}$-lauroylsarcosine solution at $50^{\circ} \mathrm{C}$ followed by RNase A treatment. After washing in $2 \times$ SSC with $0.1 \%$ $\mathrm{N}$-lauroylsarcosine, $0.2 \times$ SSC with $0.1 \% \mathrm{~N}$-lauroylsarcosine and Trisbuffered saline (TBS), the sections were treated with $1 \%$ blocking reagent (catalog \#11096176001; Roche) in TBS, pH 7.5, before antibody reaction. Then, the sections were incubated with alkaline phosphatase-conjugated anti-digoxin (1:2000, catalog \#11093274910; Roche) and chicken antiGFP antibodies (for detecting ChR2-EYFP expression, 1:800, catalog \#GFP-1020; Aves Laboratories) or goat anti-mCherry antibody (for detecting hM3Dq-mCherry expression, 1:500, catalog \#AB0040-200; SICGEN) containing $1 \%$ blocking reagent $/ \mathrm{pH} 7.5 \mathrm{TBS}$ at $4^{\circ} \mathrm{C}$. After rinsing in $\mathrm{pH} 7.5 \mathrm{TBS}$ with $0.1 \%$ Tween 20 , the sections were incubated in $1 \%$ blocking reagent containing $\mathrm{pH} 7.5 \mathrm{TBS}$. The sections were then incubated with donkey Alexa Fluor 488 anti-rat antibody (1:800, catalog \#A-21208; Thermo Fisher Scientific) or donkey Alexa Fluor 488 anti-goat antibody (1:800, catalog \#A-11055; Thermo Fisher Scientific) containing $1 \%$ blocking reagent/pH 7.5 TBS. After rinsing in $1 \%$ blocking reagent/pH 7.5 TBS (15 min, 1 time) and $\mathrm{pH} 8.0$ TBS with $50 \mathrm{~mm} \mathrm{Mg}$ solution, the sections were treated with Fast-Red solution (catalog \#F4648-50SET; Sigma-Aldrich). Sections were then washed in $\mathrm{pH} 7.5$ TBS and mounted on slide glasses.

Immunohistochemistry. Mice were anesthetized with sodium pentobarbital and then fixed by intracardiac perfusion with $4 \%$ paraformaldehyde. Then, the brains were postfixed for $24 \mathrm{~h}$ in the same fixative and cryoprotected by immersion in $30 \%$ sucrose for $2 \mathrm{~d}$. Brain sections of 30 $\mu \mathrm{m}$ thickness were cut with a cryostat. Sections were washed and blocked with PBS containing $0.25 \%$ Triton X-100 plus 3\% BSA. Then, slices were incubated with the designated primary antibodies in PBS overnight at $4^{\circ} \mathrm{C}$. Antibodies used were rat anti-GFP (1:800, catalog \#04404-84; Nacalai Tesque), goat anti-mCherry antibody (1:500, catalog \#AB0040-200; SICGEN), rabbit anti-c-Fos antibody (1:10,000, catalog \#sc-52; Santa Cruz Biotechnology), guinea pig anti-orexin B antibody (in-house, 1:500), rabbit anti-HDC antibody (1:800, catalog \#16045; Progen), mouse anti-TPH antibody (1:500, catalog \#T0678; Sigma-Aldrich), and mouse anti-TH antibody (1:2000, catalog \#sc-25269; Santa Cruz Biotechnology). Then, slices were washed with PBS three times, followed by incubation with the designated secondary antibodies in PBS for $2.5 \mathrm{~h}$. Secondary antibodies used in this study were Alexa Fluor 488-conjugated anti-rat antibody (1:800, catalog \#A-21208; Thermo Fisher Scientific), Alexa Fluor 488-conjugated anti-rabbit antibody (1:800, catalog \#A-21206 and \#A-21441; Thermo Fisher Scientific), Alexa Fluor 488-conjugated antiguinea pig antibody (1:800, catalog \#A-11073; Thermo Fisher Scientific), Alexa Fluor 594-conjugated anti-rabbit antibody (1:800, catalog \#A21207 and \#A-11037; Thermo Fisher Scientific), Alexa Fluor 594conjugated anti-goat antibody (1:800, catalog \#A-11058; Thermo Fisher Scientific), and Alexa Fluor 488-conjugated anti-mouse antibody (1:800, catalog \#A-21202; Thermo Fisher Scientific). Slices were washed three times in PBS, mounted on subbed slides, air dried, and coverslipped using Vectashield Hard Set Mounting Medium (Vector Laboratories).

Statistical analysis. Statistical analysis was conducted using Prism version 6 software (GraphPad). In optogenetic experiments, Welch's $t$ test and Student's $t$ test, respectively, were used to analyze the difference of the latency in NREM sleep and REM sleep between the ChR2- and YFPexpressing groups (see Fig. $1 F, G$ ) and paired $t$ test was used to analyze the effects of DORA (see Fig. $1 H$ ) and the effect on wakefulness after stimulation (see Fig. $3 B$ ). In chemogenetic experiments, paired $t$ test was used to analyze latencies to each sleep state and two-way repeated-measures ANOVA was used to detect significant effects of time and drug administration, followed by Bonferroni post hoc test for every $15 \mathrm{~min}$ analysis (see Fig. 4E). Two-way repeated-measures ANOVA was also applied to EEG power spectrum data (see Figs. $4 F, 5 D$ ). The Pearson correlation coefficient was calculated to estimate the strength of relation between the number of genetically manipulated neurons and wakefulness amount (see Fig. 4G). Student's $t$ test was used to compare c-Fospositive mCherry-, orexin-, TH-, HDC-, and TPH-positive neurons between the CNO- and saline-injected groups (see Fig. $4 H$ ) and Welch's $t$ test was used for c-Fos analysis to confirm the effect of CNO on hM3DqmCherry positive neurons activity (see Fig. $4 D$ ). In DREADD experiments with DORA-22 treatment, one-way repeated-measures ANOVA was used to detect significant effects on latencies to each sleep state between drug treatments, followed by Tukey's post hoc test (see Fig. 5B), and two-way repeated-measures ANOVA was used to detect significant effects of time and drug administration, followed by Tukey's post hoc test for hourly analysis (see Fig. 5C).

\section{Results}

\section{Optogenetic excitation of GABA ${ }^{\text {BNST }}$ neurons during NREM} sleep but not REM sleep triggers transition to wakefulness

To investigate whether GABA ${ }^{\text {BNST }}$ neurons play a role in the mechanism by which somnolent animals convert to a vigilant state, we examined the effect of optogenetic stimulation of these cells while monitoring sleep-wakefulness states by EEG/EMG recordings. After specifically expressing Cre-dependent ChR2EYFP in GABA ${ }^{\text {BNST }}$ neurons of GAD67-Cre mice using AAVmediated gene transfer, optic fibers were placed at the BNST (Fig. 1A). Two weeks after virus injection, EYFP-positive neurons were almost exclusively detected in neurons in the BNST with few ectopic expressions in regions outside of the BNST, including basal forebrain $(\mathrm{BF})$, caudate-putamen $(\mathrm{CPu})$, the internal capsule (ic), lateral globus pallidus (LGP), lateral preoptic area (LPO), lateral septum (LS), medial preoptic area (MPOA), and medial septum (MS) (Fig. 1B). A double-staining study suggested that these cells also expressed Gad67 mRNA (Fig. 1C).

In our preliminary study, $1 \mathrm{~Hz}$ photostimulation showed no effect, whereas $5 \mathrm{~Hz}$ stimulation evoked transition from NREM sleep to wakefulness with substantially longer time delay after the stimulation compared with $20 \mathrm{~Hz}$ stimulation. Both 10 and $20 \mathrm{~Hz}$ stimulation caused immediate transition. Stimulation with faster frequency did not cause more rapid transition compared with 20 $\mathrm{Hz}$. Based on these preliminary results, we used $20 \mathrm{~Hz}$ stimulation here.

ChR2-positive fibers were observed in several brain regions including the amygdala (central nucleus, basomedial nucleus, and amygdala-hippocampal transitional zone), hypothalamus (preoptic area, anterior hypothalamus, paraventricular nucleus, lateral hypothalamus, and mammillary nuclei), and midbrain regions [periaqueductal gray (PAG), deep mesencephalic nucleus (DpMe) and parabrachial nucleus (PBN)] (Fig. 2B, Table 1).

Laser stimulation $(473 \mathrm{~nm}, 10 \mathrm{~ms}$ width, $20 \mathrm{~Hz}$ for $20 \mathrm{~s}$ ) was delivered during NREM or REM sleep (Fig. 1D, Movie 1). We found that excitation of GABA ${ }^{\text {BNST }}$ neurons during NREM sleep resulted in immediate transition to wakefulness. The time to state transition from optical stimulation was $2.71 \pm 0.59 \mathrm{~s}(n=6)$, which was strikingly shorter than that of the control (EYFP) group $\left(295.39 \pm 106.61 \mathrm{~s}, n=6 ; t_{10}=2.35, p<0.05\right.$; Fig. $\left.1 E, F\right)$. Notably, optogenetic excitation of GABA ${ }^{\text {BNST }}$ neurons during REM sleep had no effect on sleep-wakefulness transition. The 
A

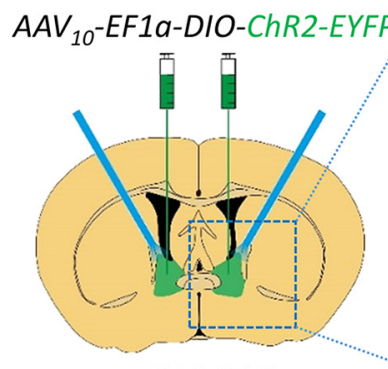

GAD67-Cre
B

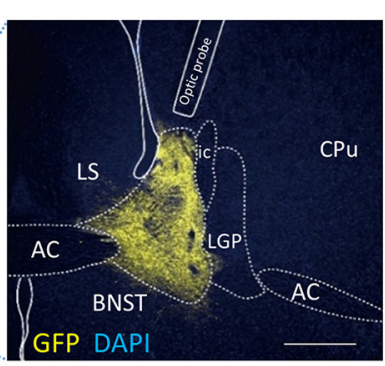

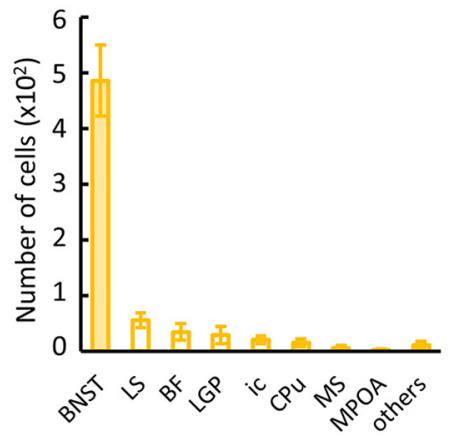

C

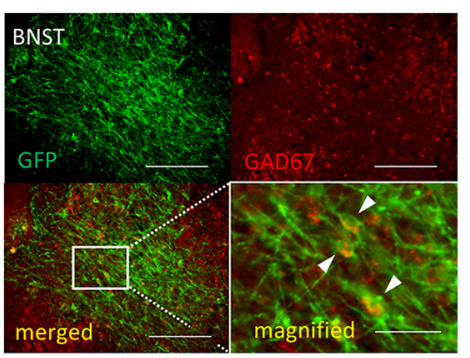

D

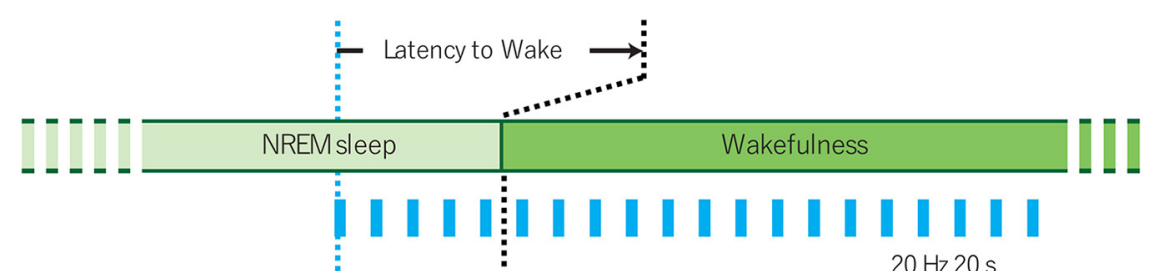

E

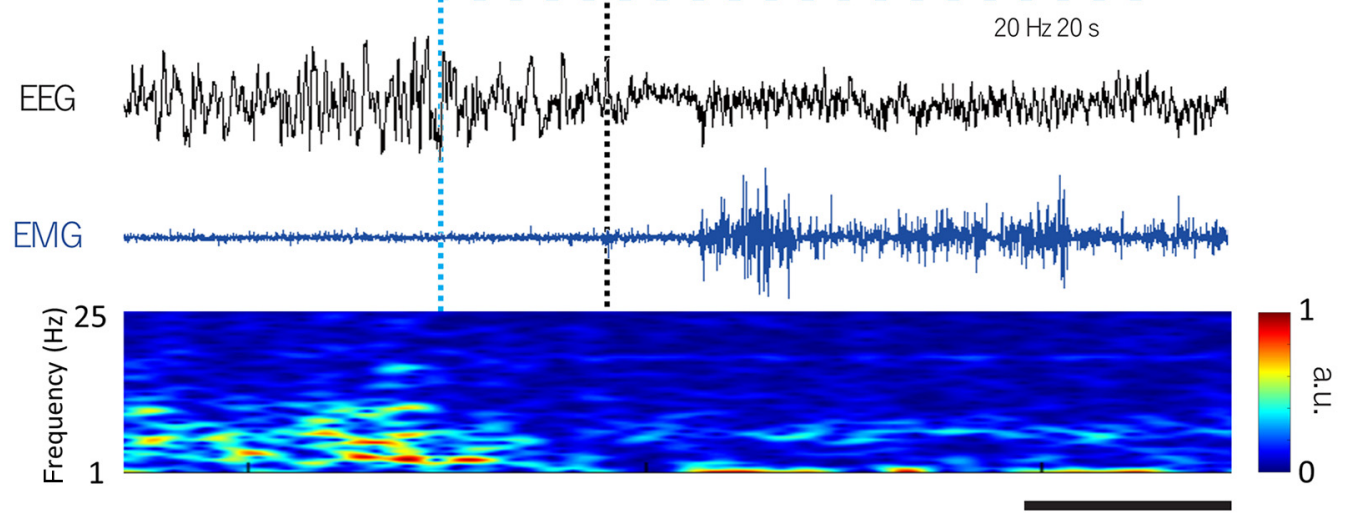

$5 s$

F

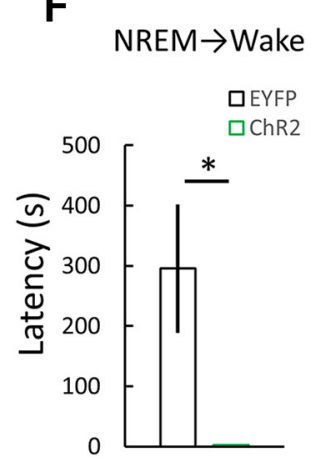

G

$\mathrm{REM} \rightarrow$ Wake

H

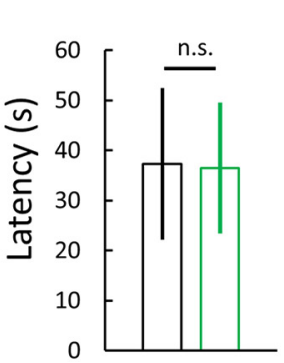

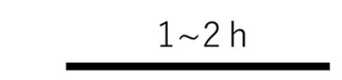

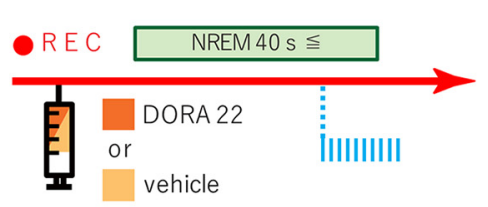

\section{NREM $\rightarrow$ Wake}

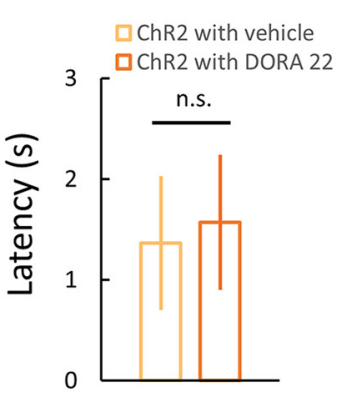

Figure 1. Optogenetic stimulation of GABA ${ }^{\text {BNST }}$ neurons induces immediate transition from NREM sleep to wakefulness. $A$, Optogenetic manipulation of GABA neurons in BNST. Left, Schematic representation of protocol. Right, Focal expression of ChR2-EYFP (yellow) in the BNST. White line shows placement of optic fiber tip. Scale bar, $250 \mu \mathrm{m}$. $\boldsymbol{B}$, Numbers of EYFP-positive cells in various brain regions after injection of $A A V_{10}$ EF1 $\alpha$-DI0-ChR2-EYFP in Gad67-Cre mice $(n=6)$. C, Top panels show fluorescent images of immunohistochemical (IHC) staining for GFP ( $g r e e n$, top left) and in situ hybridization for GAD67mRNA (red, top right). Scale bars, $200 \mu \mathrm{m}$. Bottom panels show merged images (left: $\times 10$, right: $\times 20$ ). Scale bars: left, $200 \mu \mathrm{m}$; right, $50 \mu \mathrm{m}$. D, Schematic drawing of experimental procedures. E, Representative EEG trace (top, black), EMG trace (middle, blue), and EEG power spectrum (bottom, color map; a.u., arbitrary unit) around stimulation point. Scale bar, $5 \mathrm{~s}$. $\boldsymbol{F}$, Effects of laser stimulation that induced immediate transition from NREM sleep to wakefulness. EYFP, $n=6 ;$; ChR2, $n=6$; ${ }^{*} p<0.05$, Welch's $t$ test. G, Laser stimulation did not show any change in latency of REM sleep to wakefulness. EYFP, $n=6$; ChR2, $n=6$; n.s., not significant ( $p \geq 0.05)$, Student's $t$ test. $\boldsymbol{H}$, Left, Schematic drawing of experimental procedures. Right, Laser-induced change in latency of NREM sleep to wakefulness transition after administration of DORA-22. Values are mean $\pm \mathrm{SEM}$. 3V, Third ventricle; $\mathrm{AC}$, anterior commissure; $\mathrm{LV}$, lateral ventricle.

time to wakefulness after stimulation during REM sleep was $36.45 \pm 13.08 \mathrm{~s}$ and $37.29 \pm 15.19 \mathrm{~s}$ for the EYFP- and ChR2expressing groups, respectively (EYFP, $n=6$; ChR2, $n=6 ; t_{10}=$ $0.04, p=0.484$; Fig. $1 G)$.
Hypothalamic neuropeptides, orexins, are known to play an important role in the regulation of wakefulness (Sakurai, 2007). It has also been suggested that orexin neurons receive dense innervation by the BNST (Sakurai et al., 2005; González et al., 2016) 
A

$A A V_{10}-E F 1 a-D I O-C h R 2-E Y F P$

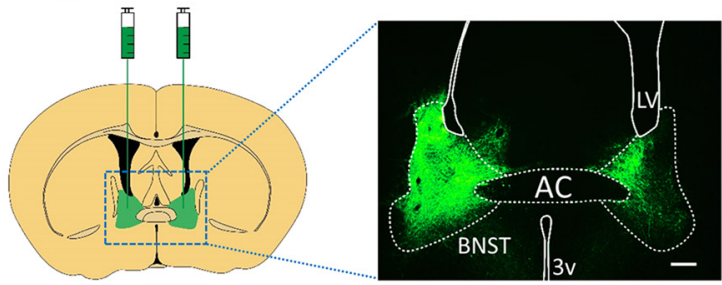

GAD67-Cre

B

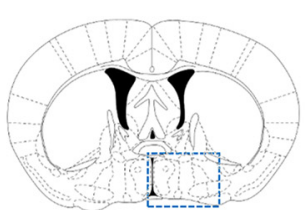

+0.02 mm
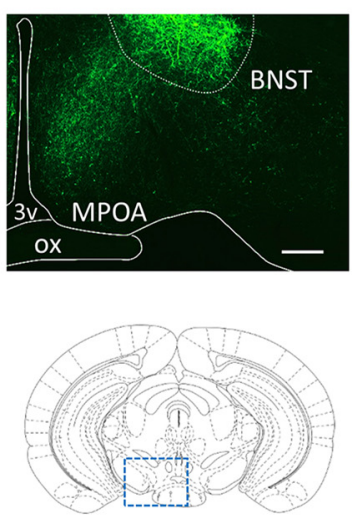

$-3.08 \mathrm{~mm}$

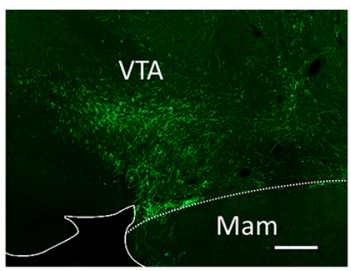

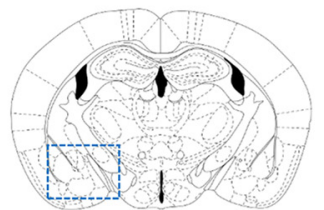

$-1.46 \mathrm{~mm}$
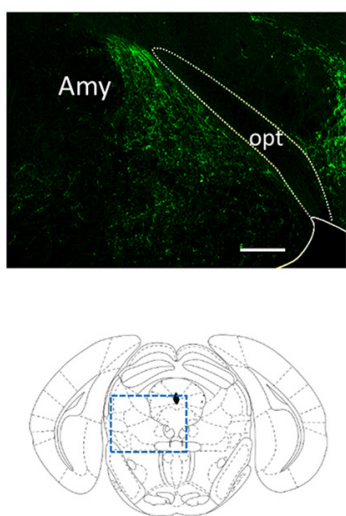

$-4.36 \mathrm{~mm}$

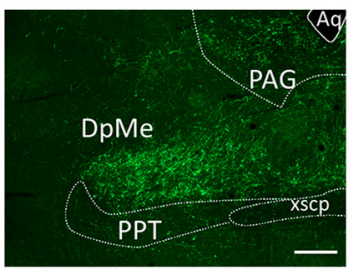

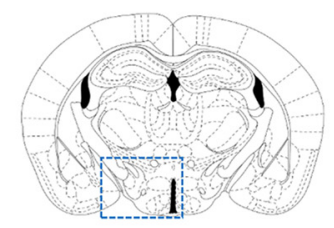

$-1.70 \mathrm{~mm}$
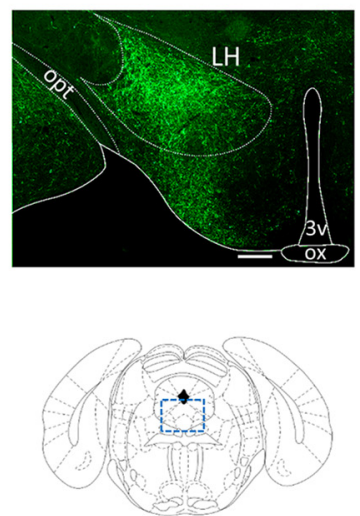

$-4.60 \mathrm{~mm}$

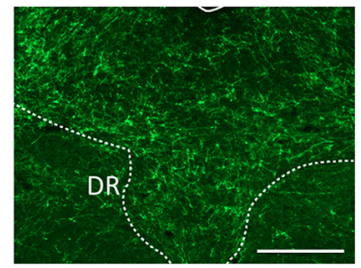

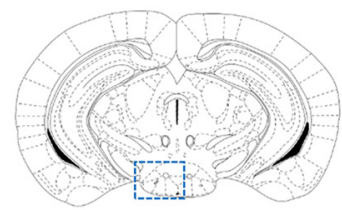

$-2.80 \mathrm{~mm}$
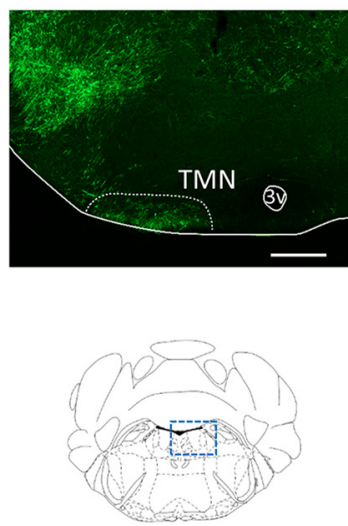

$-5.40 \mathrm{~mm}$

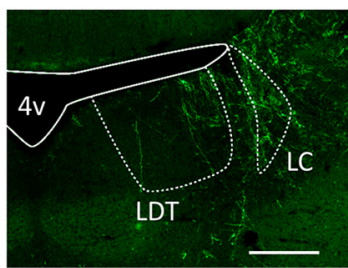

Figure 2. Projection patterns of axons of GABA ${ }^{B N S T}$ neurons. $\boldsymbol{A}$, Schematics of $A A V$ injection and representative image of expression origin. $A A V_{10}-E F 1 \alpha-D I 0-C h R 2-E Y F P$ was injected into the BNST of GAD67-Cre mice. Representative EYFP-positive neurons are shown in the right image. Scale bar, $250 \mu \mathrm{m}$. $\boldsymbol{B}$, Representative images showing EYFP-positive axonal fibers in brain regions implicated in sleep-wakefulness regulation. Distances from the bregma are shown. Each bottom image shows representative image of region shown in rectangle. Scale bars, $250 \mu \mathrm{m}$. AC, Anterior commissure; Amy, amygdala; Aq, aqueduct; LDT, laterodorsal tegmental nucleus; LH, lateral hypothalamus; Mam, mammillary nucleus; opt, optic tract; ox, optic chiasm; PPT, pedunculopontine tegmental area; VTA, ventral tegmental area; xscp, decussation of the superior cerebellar peduncle; 3V, third ventricle; 4V, fourth ventricle.

and pharmacological activation of the BNST resulted in activation of orexin neurons (Zhang et al., 2009). After injection of $A A V_{10}-E F 1 \alpha-D I O-C h R 2-E Y F P$ in the BNST of Gad67-Cre mice (Fig. 2A), we observed substantial numbers of ChR2-positive fibers in the lateral hypothalamic area (LHA) (Fig. 2B, Table 1), where orexin neurons reside, and the preoptic area, which sends abundant projections to orexin neurons (Saito et al., 2013). Therefore, we next investigated whether the orexin system plays a role in the acute arousal effect of optogenetic excitation of GABA $^{\text {BNST }}$ neurons during NREM sleep. We used DORA-22, a potent dual orexin receptor antagonist, which was administered before the stimulation. However, DORA-22 had no effect on laser-induced state transition during NREM sleep (vehicle, $n=6$,
$1.36 \pm 0.66 \mathrm{~s} ;$ DORA-22, $n=6,1.57 \pm 0.67 \mathrm{~s} ; t_{(5)}=0.44, p=$ 0.44 ; Fig. $1 H)$. This observation suggests that orexin is not involved in the state transition caused by acute excitation of GABA $^{\text {BNST }}$ neurons.

\section{Prolonged stimulation of $\mathrm{GABA}^{\mathrm{BNST}}$ neurons resulted in longer wakefulness time}

We also examined the effect of longer optogenetic stimulation of GABA $^{\text {BNST }}$ neurons during NREM sleep (Fig. 3). We repeated the stimulation 10 times every $1 \mathrm{~min}(473 \mathrm{~nm}, 10 \mathrm{~ms}$ width, $20 \mathrm{~Hz}$ for $20 \mathrm{~s}$, every $1 \mathrm{~min}$; Fig. $3 A$ ). This longer stimulation during NREM sleep resulted in significantly longer episode duration of wakefulness (single train, $n=6,206.45 \pm 103.85$ s; 10 trains, $n=6$, 
Table 1. Relative abundance of axons arising from GABA ${ }^{\text {BNST }}$ neurons

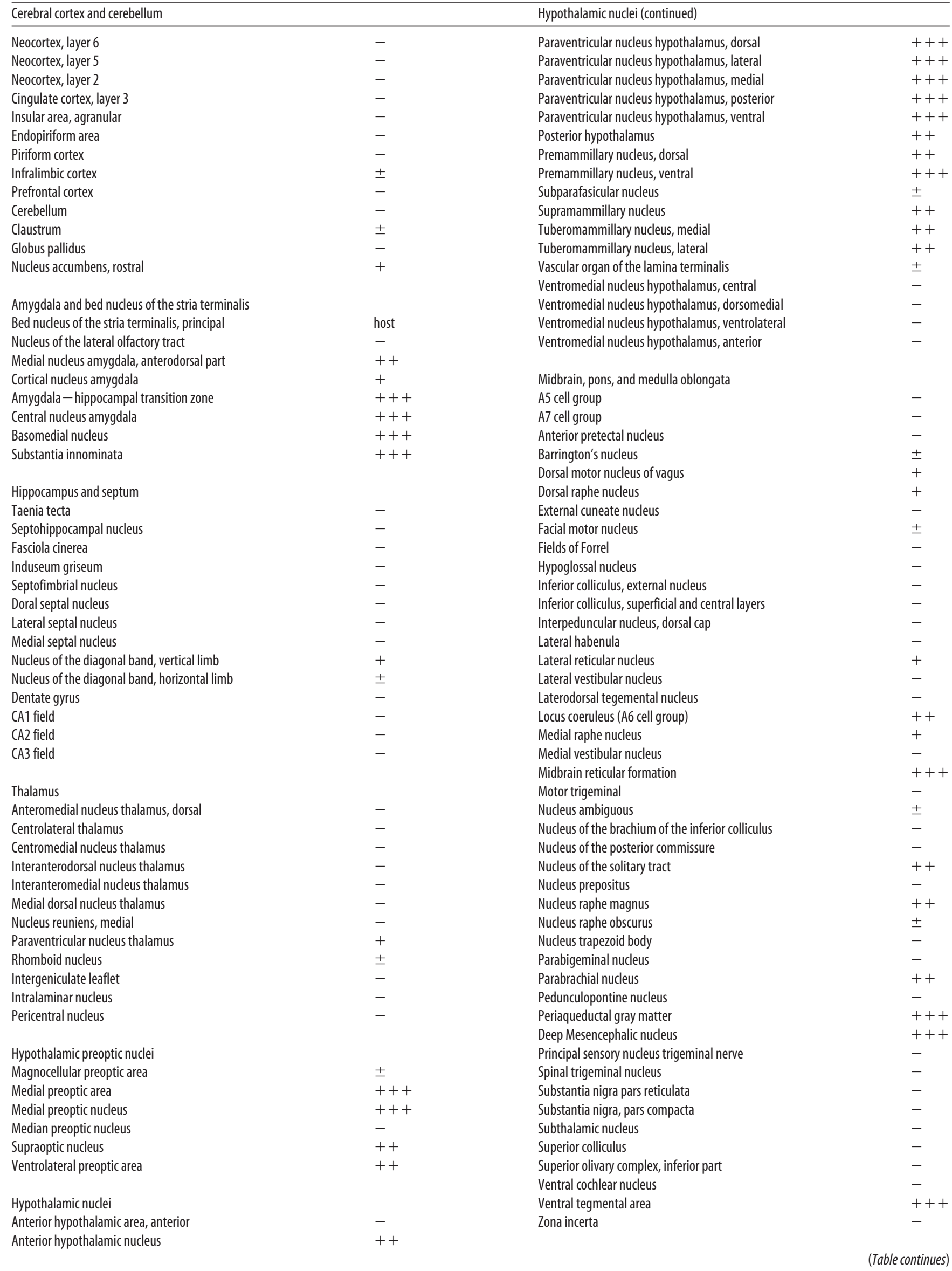


Table 1. Continued

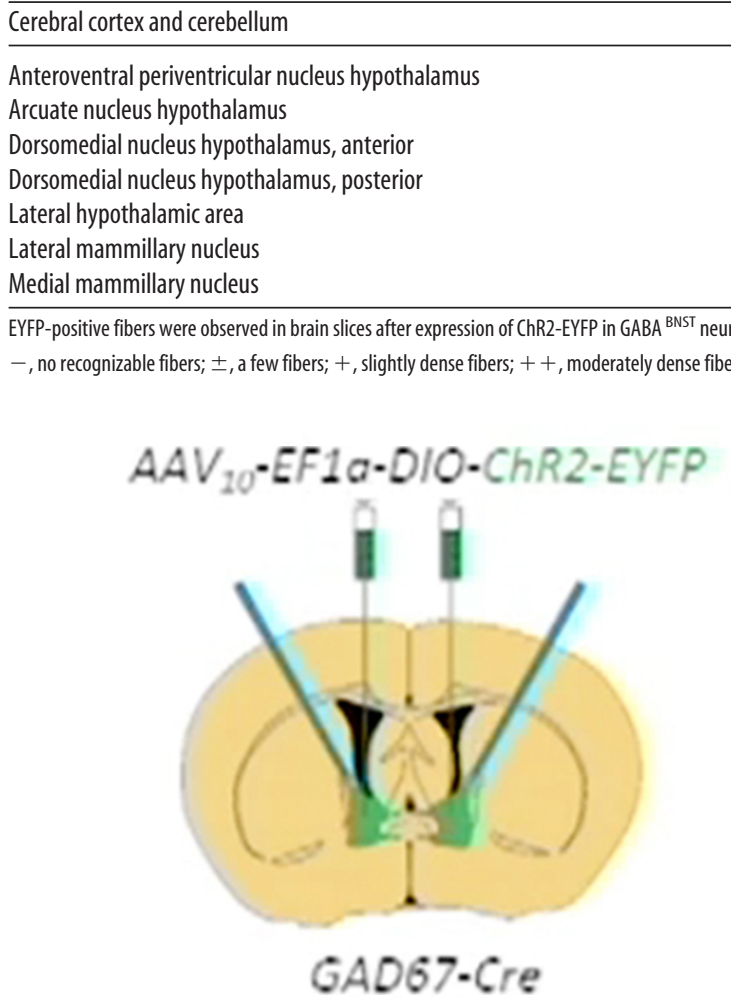

Movie 1. Optogenetic excitation of GABA ${ }^{\text {BNST }}$ neurons.

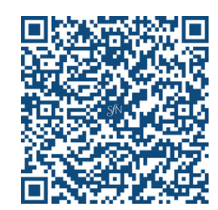

$466.27 \pm 119.05 s ; t_{(5)}=2.82, p<0.05$; Fig. $\left.3 B\right)$. The prolonged stimulation also resulted in an increase of wakefulness time, along with a decrease in both NREM and REM sleep (Fig. 3C).

To make prolonged manipulation of GABA ${ }^{\text {BNST }}$ neurons easier, we used a chemogenetic strategy (DREADD) (Armbruster et al., 2007; Roth, 2016) to stimulate these cells. $A A V_{10}$-EF1a-DIO$h M 3 D q-m C h e r r y$ was injected bilaterally in the BNST of GAD67Cre mice (Fig. 4A). Histological observations suggested that hM3Dq-mCherry-positive neurons were almost exclusively observed within the area of the BNST. Small numbers of mCherrypositive neurons were also detected outside of the BNST area (e.g., BF, CPu, ic, LGP, LPO, LS, MS, and MPOA; Fig. 4B). A double-staining study showed that these cells expressed Gad67 mRNA (Fig. 4C). After expressing hM3Dq-mCherry specifically in GABA ${ }^{\text {BNST }}$ neurons, saline or CNO was intraperitoneally administered at ZT4.0 and mice were subjected to sleep analysis by EEG/EMG recording (Fig. 4E).

DREADD-mediated activation of GABA ${ }^{\text {BNST }}$ neurons was evaluated as c-Fos-immunostaining (saline, $n=5,5.47 \pm 0.73 \%$; $\mathrm{CNO}, n=5,58.42 \pm 4.18 \%$; $t_{(8)}=6.61, p<0.001$; Fig. $\left.4 D\right)$. We also observed an increase in wakefulness $30-75$ min after CNO administration compared with control injection. Wakefulness time for saline and $\mathrm{CNO}$ groups, respectively, were as follows: 30 $\min , 60.42 \pm 7.42 \%$ and $81.3 \pm 7.04 \%, p<0.05 ; 45 \mathrm{~min}, 29.86 \pm$ $7.31 \%$ and $63.82 \pm 9.11 \%, p<0.001 ; 60 \mathrm{~min}, 10.43 \pm 2.61 \%$ and $41.96 \pm 9.60 \%, p<0.001 ; 75 \mathrm{~min}, 18.38 \pm 5.78 \%$ and $40.10 \pm$ $7.92 \%, p<0.05\left(n=17, F_{(1,16)}=11.71, p<0.01\right.$; Fig. $\left.4 E\right)$. NREM sleep time were decreased as follows: $45 \mathrm{~min}, 66.09 \pm$
$6.80 \%$ and $36.18 \pm 9.11 \%, p<0.001 ; 60 \mathrm{~min}, 79.50 \pm 2.79 \%$ and $56.99 \pm 9.46 \%, p<0.05\left(n=17, F_{(1,16)}=4.97, p<0.05\right.$; Fig. $\left.4 E\right)$. Notably, CNO administration decreased REM sleep amount for a longer period: $60 \mathrm{~min}, 10.07 \pm 1.48 \%$ and $1.05 \pm 1.05 \%, p<$ $0.001 ; 75 \mathrm{~min}, 8.97 \pm 1.71 \%$ and $0.86 \pm 0.60 \%, p<0.001 ; 90$ $\min , 9.15 \pm 1.58 \%$ and $3.40+1.69 \%, p<0.01 ; 105 \mathrm{~min}, 10.30 \pm$ $2.10 \%$ and $0.24 \pm 0.24 \%, p<0.001 ; 120 \mathrm{~min}, 7.53 \pm 1.96 \%$ and $1.10 \pm 0.60 \%, p<0.001\left(n=17, F_{(1,16)}=110.9, p<0.001\right.$; Fig. $4 E)$. This effect continued for $4 \mathrm{~h}$ after $\mathrm{CNO}$ administration (ZT4.0-ZT8.0: $8.17 \pm 0.45 \%$ and $2.86 \pm 0.51 \% ; n=17, t_{(16)}=$ 8.98, $p<0.001$; data not shown) compared with NREM sleep. The latencies to NREM and REM sleep were also markedly lengthened in the CNO-administered group (NREM sleep: saline, $n=$ $17,18.38 \pm 2.23 \mathrm{~min} ; \mathrm{CNO}, n=17,42.30 \pm 6.44 \mathrm{~min} ; t_{(16)}=$ 4.25, $p<0.001$; REM sleep: saline, $n=17,47.10 \pm 6.84 \mathrm{~min}$; $\mathrm{CNO}, n=17,158.26 \pm 18.08 \mathrm{~min} ; t_{(16)}=5.52, p<0.001$; Fig. $4 E$ ). Because off-target expression of hM3Dq was very small (Fig. $4 B$ ), we postulated that the effects of CNO observed in this study mainly resulted from the excitation of $\mathrm{GABA}^{\mathrm{BNST}}$ neurons. Moreover, to assess the degree of the AAV-mediated gene transfer, we quantified numbers of mCherry-positive cells for each experimental animal. We plotted the length of wakefulness for $2 \mathrm{~h}$ after CNO administration over numbers of positive neurons in each sample. We found a positive correlation between the number of mCherry-positive cells in the BNST $(n=17, r=0.43, p<$ $0.05)$, but not BF $(n=17, r=-0.13, p=0.31)$, suggesting that there was a close relationship between excitation of GABA ${ }^{\text {BNST }}$ neurons and arousal duration (Fig. 4G).

We next examined the effect of the DREADD-mediated excitation of GABA ${ }^{\text {BNST }}$ neurons on the quality of NREM sleep. The power spectral profiling of EEG for $2 \mathrm{~h}$ after the stimulation suggests that the pharmacogenetic excitation of GABA ${ }^{\text {BNST }}$ neurons did not evoke significant effect on the power profile in NREM sleep (two-way repeated-measures ANOVA, $n=17$, $F_{(1,16)}=0.059, p=0.81$; Fig. $\left.4 F\right)$.

\section{Orexin plays a role in increase in wakefulness induced by DREADD excitation of GABA ${ }^{\text {BNST }}$ neurons}

Orexin is known to play an important role in the maintenance of wakefulness rather than in the vigilance state transition itself (Sakurai, 2007). The longer episode duration of wakefulness after longer optogenetic stimulation (Fig. 3) and DREADD (Fig. 4E) prompted us to investigate whether the orexin system is mobilized after prolonged excitation of GABA ${ }^{\text {BNST }}$ neurons, which leads to longer wakefulness episode duration, although we found that the immediate state transition by the optogenetic stimulation was not affected by DORA-22 (Fig. $1 H$ ).

To determine the involvement of orexin neurons in the arousal actions by DREADD-induced excitation of GABA ${ }^{\text {BNST }}$ neurons, we first examined the activity of orexin neurons using c-Fos immunostaining (Fig. $4 H$ ). Because we found that the 
A
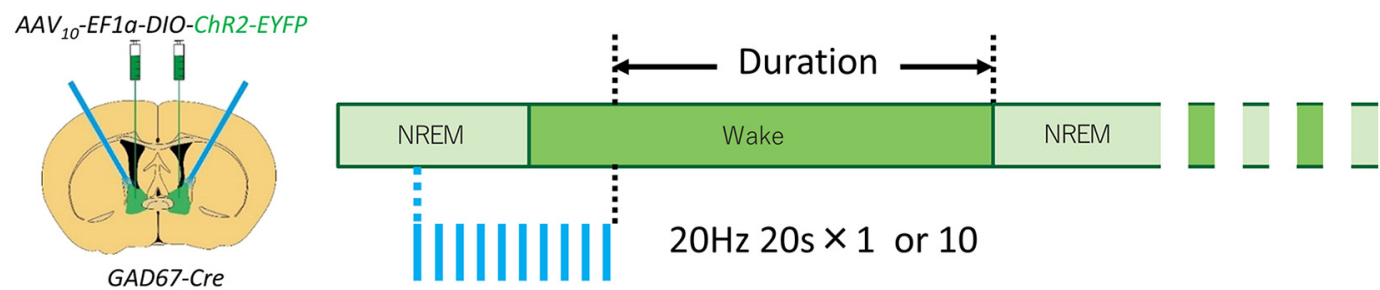

B

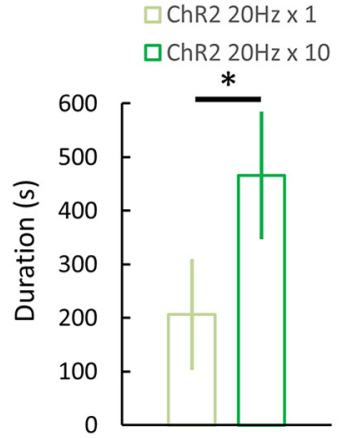

C
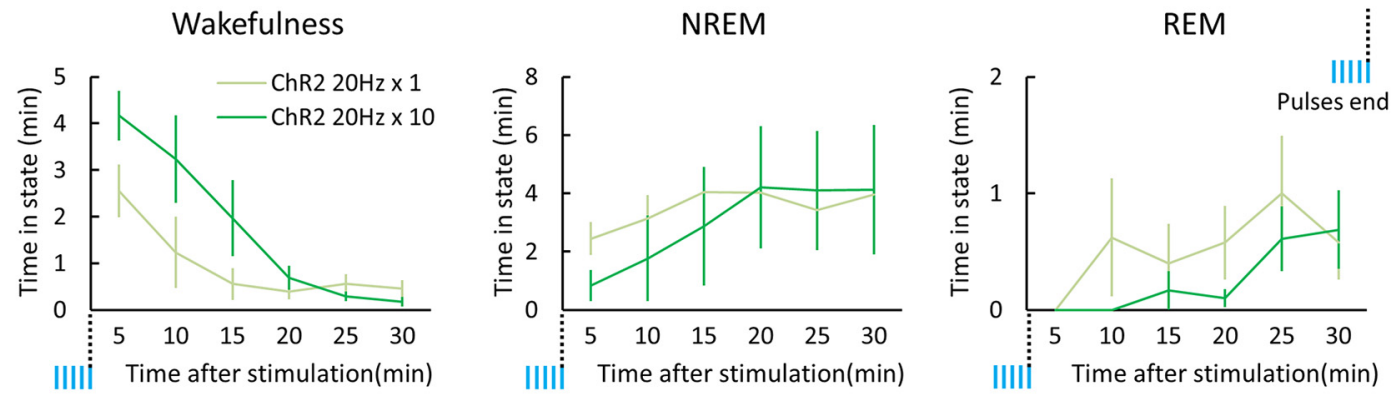

Figure 3. Longer stimulation of GABA ${ }^{\text {BNST }}$ neurons during NREM sleep evoked more sustained wakefulness. $A$, Experimental procedures. Twenty seconds of $20 \mathrm{~Hz}$ pulses were applied 1 or 10 times (every $1 \mathrm{~min}$ ) at ZT4.0 -ZT10.0. Duration of the first wakefulness episode after the laser-induced transition to wakefulness was measured. $\boldsymbol{B}$, Episode duration of laser-induced wakefulness. Values are mean \pm SEM. ${ }^{*} p<0.05$, paired $t$ test. $C$, Vigilance state time for every 5 min plotted just after the end of stimulation.

arousal effect by $\mathrm{CNO}$ administration emerged 30 min after the injection (Fig. 4E) and it is assumed that c-Fos expression would be observed after $\sim 90$ min after the maximal excitation of neurons (Xiu et al., 2014), mice were killed and their brains were fixed $2 \mathrm{~h}$ after $\mathrm{CNO}$ administration. The proportion of c-Fosexpressing orexin neurons was significantly larger in the CNOtreated group than in the control group (saline, $n=9,12.06 \pm$ $3.34 \%$; CNO, $n=8,27.68 \pm 6.03 \% ; t_{(15)}=2.34, p<0.05$; Fig. $4 H)$. These data suggest that excitation of GABA ${ }^{\text {BNST }}$ neurons for a substantial time period mobilizes the function of orexin neurons.

To examine the effect of DREADD stimulation of GABA ${ }^{\text {BNST }}$ neurons on other arousal related regions, we also examined c-Fos expression in the locus ceruleus (LC), tuberomammillary nucleus (TMN), and dorsal raphe (DR) after $\mathrm{CNO}$ administration (Fig. $4 H$ ). We found that the pharmacogenetic excitation of GABA $^{\text {BNST }}$ neurons resulted in significant increase of c-Fos expression in TH-positive noradrenergic neurons in the LC (saline, $n=9,4.16 \pm 0.51 \%$; CNO, $n=8,11.60 \pm 2.34 \% ; t_{(15)}=2.73$, $p<0.01$; Fig. $4 H$ ). However, we failed to observe an increase of c-Fos expression in HDC-positive histaminergic neurons in the TMN (saline, $n=9,1.70 \pm 0.44 \%$; CNO, $n=8,3.99 \pm 1.65 \%$; $t_{(15)}=1.29, p=0.11$; Fig. $\left.4 H\right)$ and TPH-positive serotonergic neurons in the DR (saline, $n=9,2.36 \pm 0.91 \%$; CNO, $n=7$, $1.82 \pm 0.57 \% ; t_{(14)}=0.47, p=0.32$; Fig. $4 H$ ). This suggests that excitation of GABA ${ }^{\text {BNST }}$ neurons leads to activation of noradrenergic neurons in the LC.

Because we found activation of orexin neurons after excitation of GABA ${ }^{\text {BNST }}$ neurons by DREADD (Fig. $4 H$ ), we next investigated whether the orexin system actually plays a role in the increase of wakefulness amount by excitation of GABA ${ }^{\text {BNST }}$ neurons. We used a dual orexin receptor antagonist, DORA-22, to block orexinergic neurotransmission (Fig. 5A). The CNOinduced increase in latency to NERM sleep was abolished by administration of DORA-22 (vehicle $+\mathrm{CNO}, 29.91 \pm 5.23 \mathrm{~min}$; DORA-22 + CNO, $6.49 \pm 2.45$ min; one-way repeated-measures
ANOVA, $n=9, F_{(3,24)}=16.39, p<0.001$; Tukey's post hoc test, $p<0.01$; Fig. $5 B$ ). The DREADD-induced increase in wakefulness amount was also significantly attenuated by administration of DORA-22 at ZT4.0 (vehicle + CNO, $61 \pm 8 \%$; DORA-22 + $\mathrm{CNO}, 33 \pm 6 \%$; two-way repeated-measures ANOVA, $n=9$, $F_{(3,24)}=2.93, p=0.054$; Tukey's post hoc test, $p<0.001$; Fig. $5 C$ ). This alteration was accompanied by an increase in NREM sleep time by DORA-22 (vehicle $+\mathrm{CNO}, 39 \pm 8 \%$; DORA- $22+\mathrm{CNO}$, $63 \pm 6 \%$; two-way repeated-measures ANOVA, $n=9, F_{(3,24)}=$ 3.30, $p<0.05$; Tukey's post hoc test, $p<0.001$; Fig. $5 C$ ).

Interestingly, DORA-22 did not affect the DREADD-induced increase in latency to REM sleep (vehicle $+\mathrm{CNO}, 133.2 \pm 28.86$ min; DORA-22 + CNO, $91.83 \pm 26.53 \mathrm{~min}$; one-way repeatedmeasures ANOVA, $n=9, F_{(3,24)}=6.41, p<0.05$; Tukey's post hoc test, $p=0.73$; Fig. $5 B$ ) or the decrease in REM sleep amount (ZT4.0-8.0: vehicle + CNO, $4.06 \pm 1.04 \%$; DORA-22 + CNO, $4.36 \pm 0.97 \%$; paired $t$ test, $n=9, t_{(8)}=0.22, p=0.42$; Fig. $5 C$ ).

NREM sleep mean relative EEG power spectrum for $2 \mathrm{~h}$ after saline or CNO administration did not show any significant effect within each group (two-way repeated-measures ANOVA, $n=9$, $F_{(3,24)}=0.46, p=0.71$; Fig. $\left.5 D\right)$.

These observations suggest that the orexin system plays a role in sustaining wakefulness after prolonged activation of GABA ${ }^{\text {BNST }}$ neurons, mainly by inhibiting NREM sleep rather than REM sleep.

\section{Discussion}

\section{Excitation of GABA ${ }^{\text {BNST }}$ neurons triggers transition from NREM sleep to wakefulness sleep without function of orexin system}

One of the hallmarks after exposure of animals to an emotionally salient environment is an increase in vigilance, wakefulness, and arousal as an adaptive response to environmental situations (Saper et al., 2010; Sakurai, 2014). Conversely, the mechanisms by which the limbic system drives wakefulness might cause hyperarousal when it is inappropriately activated. In fact, psychiatric conditions such as anxiety disorders, posttraumatic stress 
A

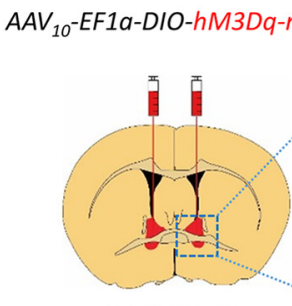

GAD67-Cre
B

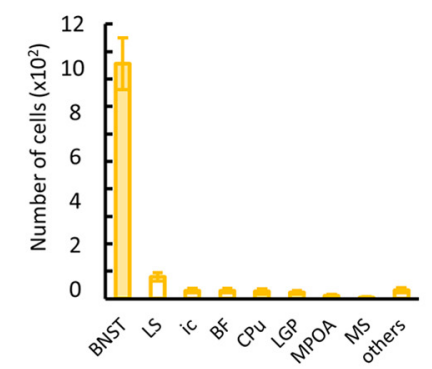

C

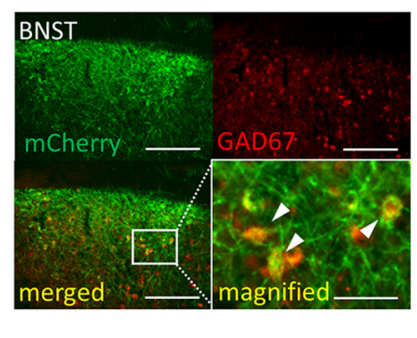

D

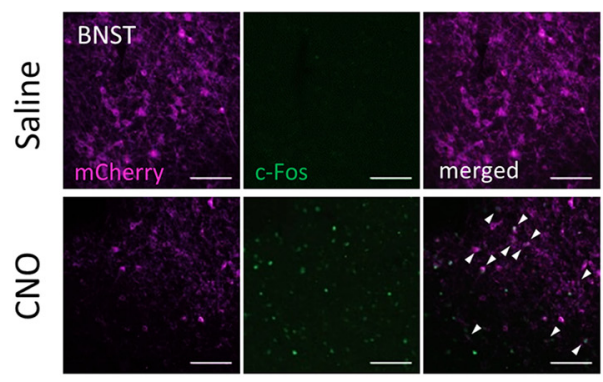

E

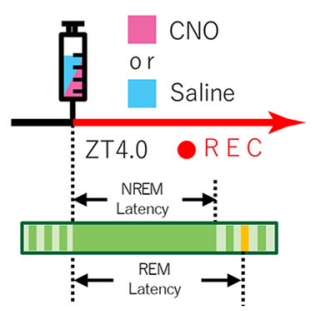

[) Wakefulness 7 REM sleep

( NREM sleep

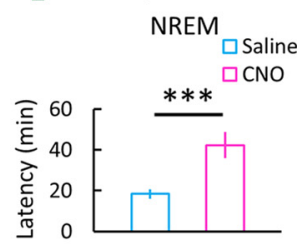

REM

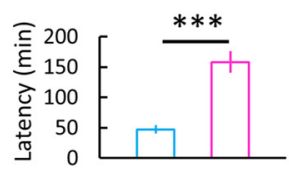

F
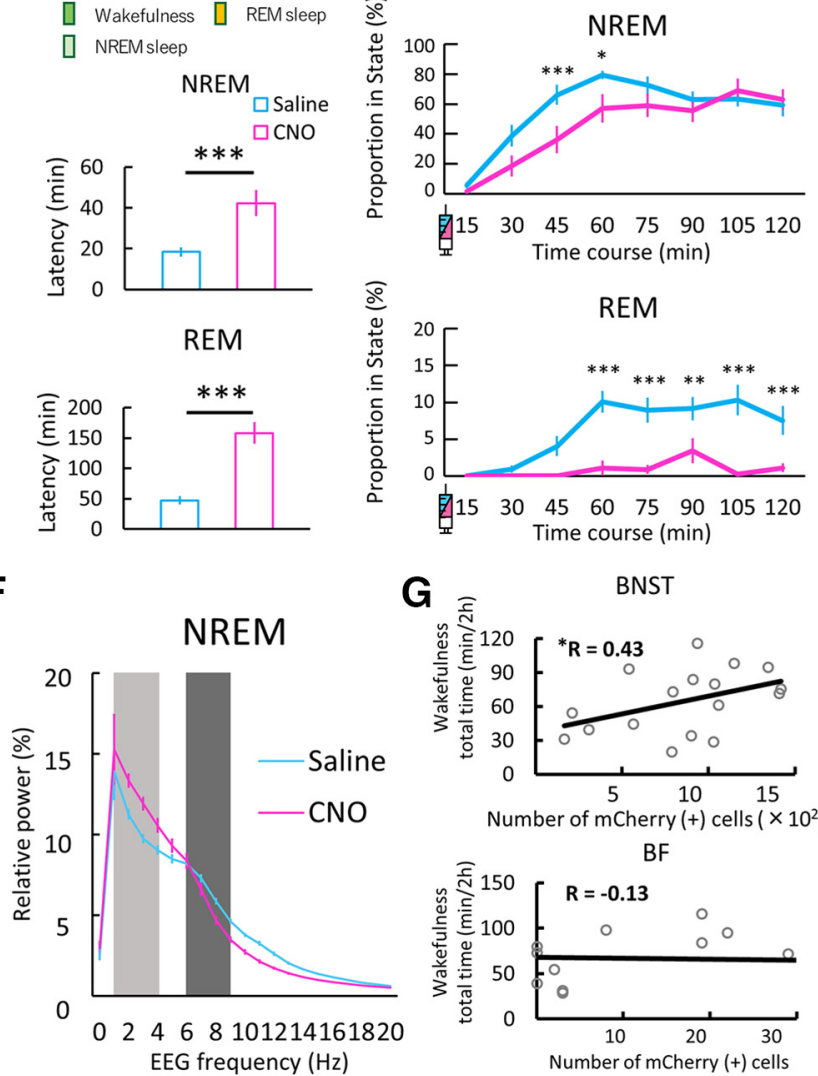

G
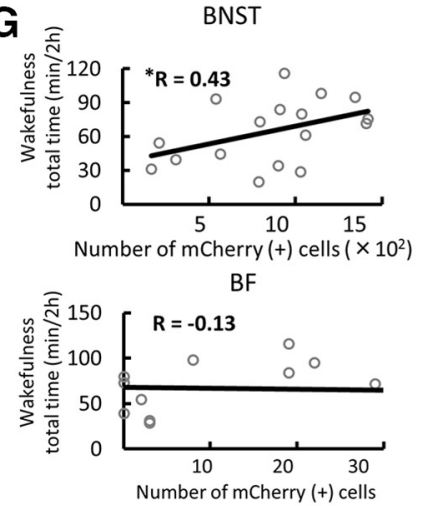

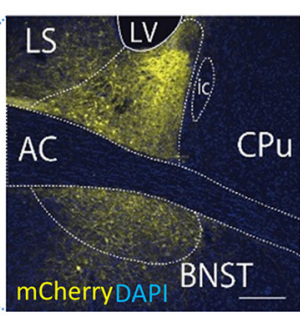

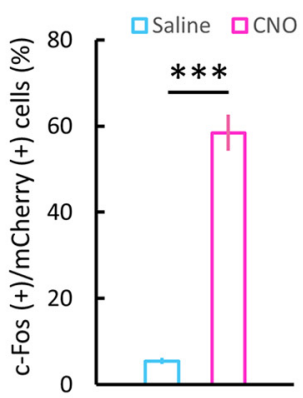

H

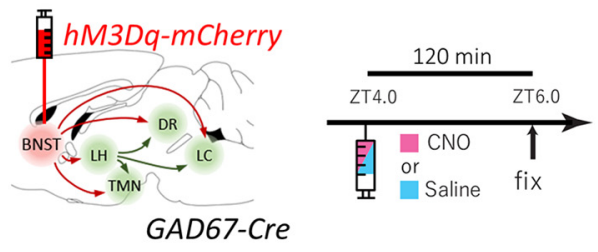

Saline

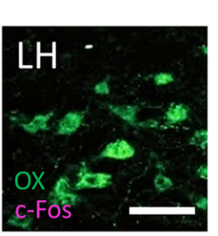

CNO

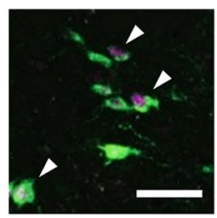

$\square$ Saline $\square$ CNO
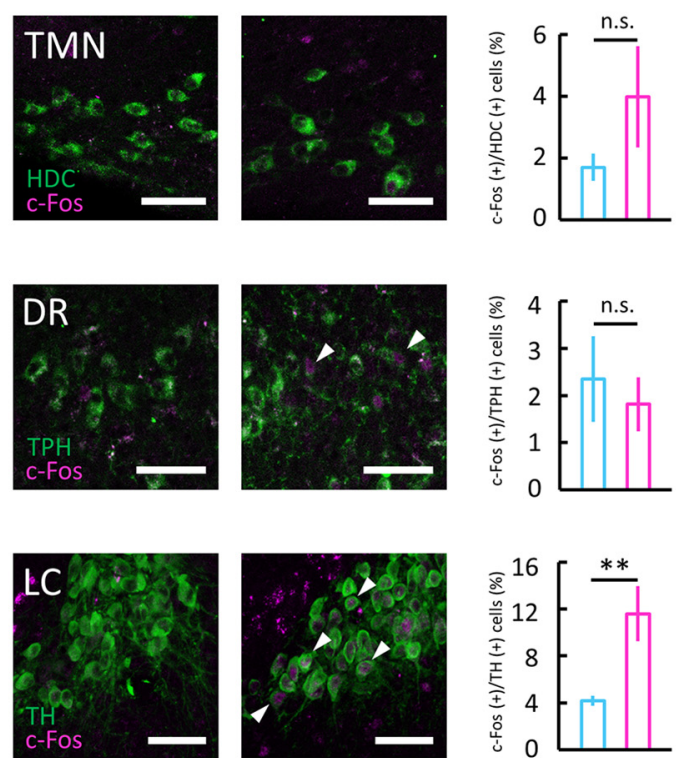

Figure 4. DREADD-mediated excitation of GABA ${ }^{\text {BNST }}$ neurons induced wakefulness. $A$, Left, Schematic representation of AAV injection. AAV $10^{-E F 1 a-D I O-h M 3 D q-}$ Cherry was injected bilaterally into the BNST (red area) of Gad67-Cre mouse. Right, Image (area of blue rectangle in left panel) showing focal expression of hM3Dq-mCherry (yellow) in the BNST counterstained with DAPI (blue). Scale bar, $250 \mu \mathrm{m}$. B, Numbers of mCherry-positive cells in various brain regions after injection of AAV 10 -EF1a-DI0-hM3Dq-mCherry in Gad67-Cre mice $(n=17)$. (Figure legend continues.) 
disorder, and depression are usually accompanied by sleep disturbance (Khazaie et al., 2016).

Because the BNST is implicated in anxiety and stress (Davis et al., 2010; Lebow and Chen, 2016), we examined here the effect of manipulation of this region on sleep-wakefulness states in mice. Because the major neuronal population of the BNST is GAD67expressing GABAergic neurons (Kudo et al., 2012; Lebow and Chen, 2016), we manipulated these GABA ${ }^{\text {BNST }}$ neurons at different stages of sleep-wakefulness states. We found that acute optogenetic activation of GABA ${ }^{\mathrm{BNST}}$ neurons caused immediate transition from NREM sleep to wakefulness with an $\sim 3 \mathrm{~s}$ delay from the start of stimulation. The location of BNST is close to the $\mathrm{BF}$ and optogenetic stimulation of the GABAergic neurons in these areas have been shown recently to cause arousal (Anaclet et al., 2015; Xu et al., 2015) and to increase cortical gamma oscillations (Kim et al., 2015). However, because spillover of the ChR2 expression into these areas was very small (Fig. $1 B$ ) and tips of optic fibers were precisely placed at the position of the BNST in all samples, it is not likely that the effects observed in this study were due to stimulation of these cells.

This quick transition was not blocked by DORA-22, suggesting that the immediate transition from NREM sleep to wakefulness by BNST activation does not require the function of orexin.

\section{Prolonged excitation of GABA ${ }^{\text {BNST }}$ neurons mobilizes orexin system to stabilize wakefulness}

We also examined the effect of more sustained excitation of $\mathrm{GABA}^{\mathrm{BNST}}$ neurons by a chemogenetic method (DREADD). DREADD-mediated stimulation of GABA ${ }^{\text {BNST }}$ neurons significantly increased wakefulness time for $1 \mathrm{~h}$, along with decreases in NREM and REM sleep amounts (Fig. 4E). Latencies to each sleep

\section{$\leftarrow$}

(Figure legend continued.) C, Top, Fluorescent images of immunohistochemical (IHC) staining for mCherry (green, top left) and in situ hybridization for Gad67 mRNA (red, top right) in BNST. Scale bars, $200 \mu \mathrm{m}$. Bottom, Merged images (left: $\times 10$, right: $\times 20$ ). Scale bars: left, $200 \mu \mathrm{m}$; right, $50 \mu \mathrm{m}$. D, Left, Representative images showing IHC staining for hM3Dq-mCherry (magenta, left) and c-Fos (green, middle) in GABA ${ }^{\text {BNST }}$ neurons in the light period. CNO (bottom) increased c-Fos expression in hM3Dq-expressing GABA ${ }^{\text {BNST }}$ neurons compared with saline (top). Arrowheads indicate c-Fos $(+) / h M 3 D q-m$ Cherry $(+)$ cells in GABA ${ }^{\text {BNST }}$ neurons. Scale bars, $100 \mu \mathrm{m}$. Right, Proportion of c-Fos $(+) / \mathrm{mCherry}(+)$ cells in GABA ${ }^{\text {BNST }}$ neurons was significantly larger in the CNO group (magenta) compared with control (blue). Values are mean \pm SEM. Saline, $n=5$; CNO, $n=5$; ${ }^{* * *} p<0.001$, Welch's $t$ test. E, Left, Schematic drawing of experimental procedures. Saline or CNO $(5.0 \mathrm{mg} / \mathrm{kg})$ was intraperitoneally administered at ZT4.0 and mice were subjected to EEG/EMG recording. Graphs below the schema represent the latency time from wakefulness to NREM (top) or REM (bottom) sleep after drug administration. Saline, $n=17 ; \mathrm{CN} 0, n=17 ;{ }^{* *} p<0.001$, paired $t$ test. Values are mean \pm SEM. Right, Change in proportion of each state (top, wakefulness; middle, NREM sleep; bottom, REM sleep) after saline (blue) or CNO (magenta) administration. Saline, $n=17$; CNO, $n=17$; two-way repeated-measures ANOVA followed by Bonferroni post hoc test, ${ }^{*} p<0.05$, ${ }^{* *} p<$ $0.01,{ }^{* * *} p<0.001 . \boldsymbol{F}$, EEG power density shown as the mean percentage of total EEG power \pm SEM in saline- and CNO-administered groups for $2 \mathrm{~h}$ after injection ( $n=17$ per group) for $1 \mathrm{~Hz}$ frequency bins between 0 and $20 \mathrm{~Hz}$. The delta $(1-4 \mathrm{~Hz}$, light dark) and theta $(6-9 \mathrm{~Hz}$, dark) ranges are indicated by shaded areas. No statistically significant differences were observed between groups ( $n=17, F_{(1,16)}=0.059, p=0.81$, two-way repeated-measures ANOVA). $G$, Correlations between wakefulness time and number of hM3Dq-mCherry-positive cells in the BNST (top) and BF (bottom) for $2 \mathrm{~h}$ after CNO administration. $\boldsymbol{H}$, Effect of GABA ${ }^{\text {BNST }}$ neurons excitation by DREADD on c-Fos expression (magenta) of orexin and monoamine neurons (green) for c-Fos analysis. Arrowheads indicate c-Fos-positive orexin or monoamine neurons. Scale bars, $50 \mu \mathrm{m}$. $\mathrm{hM} 3 \mathrm{Dq}$-expressing mice were killed $2 \mathrm{~h}$ after saline or CNO $(5.0 \mathrm{mg} / \mathrm{kg})$ was administered intraperitoneally at ZT4.0. The graphs show the percentage of c-Fos-positive neurons in each area in saline- (blue) and CNO (magenta)-administered group. Values are mean \pm SEM. Saline, $n=9 ;(\mathrm{NO}, n=8$ (orexin, $\mathrm{HDC}$ and TH) and saline, $n=9 ;(\mathrm{NO}, n=7$ (TPH); n.s., not significant $(p \geq 0.05),{ }^{*} p<0.05,{ }^{* *} p<0.01$, Student's $t$ test. AC, Anterior commissure; LH, lateral hypothalamus; LV, lateral ventricle; $0 \mathrm{X}$, orexin. state were also lengthened (Fig. 4E). The effect on REM sleep was longer than that on wakefulness and NREM sleep (Figs. 4E, 5C), suggesting that excitation of $\mathrm{GABA}^{\mathrm{BNST}}$ neurons had a stronger influence on REM sleep compared with NREM sleep. This suggests that different neuronal pathways are driven by GABA ${ }^{\text {BNST }}$ neurons to inhibit NREM and REM sleep.

We found prolonged excitation of GABA ${ }^{\text {BNST }}$ neurons evoked by DREADD, which induced longer wakefulness episode duration accompanied by an increase in c-Fos-positive orexin neurons (Fig. 4H). This was consistent with a previous report suggesting that disinhibition of the BNST increased c-Fos expression in orexin neurons (Zhang et al., 2009). These observations prompted us to investigate whether prolonged excitation of GABA $^{\text {BNST }}$ neurons might mobilize the orexin system to sustain wakefulness. To evaluate this hypothesis, we used a dual orexin receptor antagonist, DORA-22. The CNO-induced increase in wakefulness and prolonged latency to NREM sleep was suppressed by pretreatment with DORA-22 (Fig. $5 B, C$ ). These observations strongly suggest that the function of the orexin system is necessary for prolonged wakefulness induced by sustained excitation of GABA ${ }^{\text {BNST }}$ neurons.

Previous studies have suggested that pharmacological disinhibition of the BNST results in elevated sympathetic tone in wildtype mice, but not in mice that lack orexin neurons or the orexin gene (Zhang et al., 2009). The control of cardiovascular function through activation of sympathetic outflow is fundamental in stressful environments, which also requires animals to sustain wakefulness to ensure adaptive behavior. This suggests that activation of orexin neurons also plays an important role in sustaining arousal through the influence of the limbic system. A recent report suggested that the orexin signaling plays a role in the facilitation of cue-induced reinstatement of alcohol seeking induced by neuropeptide S (Ubaldi et al., 2016). This suggests a reciprocal interaction between orexin neurons in the LHA and BNST neurons.

Mazzone et al. (2016) reported that stimulation of vesicular GABA transporter-expressing BNST neurons by DREADD promotes anxiety-like behavior. Our present study suggests that this activation also evokes wakefulness.

In our experiments, REM sleep reduction was observed for a longer time compared with NREM sleep after chemogenetic excitation of GABA ${ }^{\text {BNST }}$ neurons (Fig. $4 E$ ). Considering previous reports showing that intracerebroventricular orexin administration or chemogenetic excitation of orexin neurons in the light period decreases NREM and REM sleep with a similar time course (Mieda et al., 2011; Sasaki et al., 2011), it is suggested that the later phase REM sleep suppression after DREADD-mediated activation of $\mathrm{GABA}^{\mathrm{BNST}}$ neurons is caused by mechanisms other than activation of orexin neurons. In fact, a dual orexin receptor antagonist, DORA-22, had no effect on REM sleep suppression induced by DREADD (Fig. $5 B, C$ ).

Because the BNST has widespread ascending and descending projections, we examined the projection pattern of GABA ${ }^{\mathrm{BNST}}$ neurons. After expressing ChR2 in GABA ${ }^{\mathrm{BNST}}$ neurons, ChR2positive fibers were observed in the midbrain, including the MPOA, PAG, DpMe, and PBN (Fig. 2B, Table 1), all regions implicated in REM sleep regulation (Dong et al., 2001; Dong et al., 2003, 2004, 2006a, b, c; Saper et al., 2010; Hayashi et al., 2015; Van Dort et al., 2015). These observations suggest that excitation of GABA ${ }^{\text {BNST }}$ neurons might act directly on these regions to inhibit REM sleep without involvement of the orexin system.

Our optogenetic stimulation study showed that acute excitation of GABA ${ }^{\text {BNST }}$ neurons during REM sleep failed to evoke a rapid transition to wakefulness (Fig. $1 F$ ). Several studies using 
A

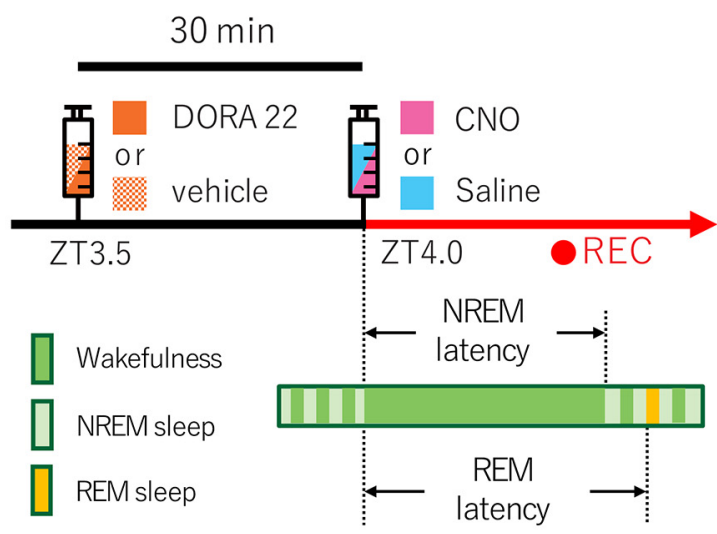

B
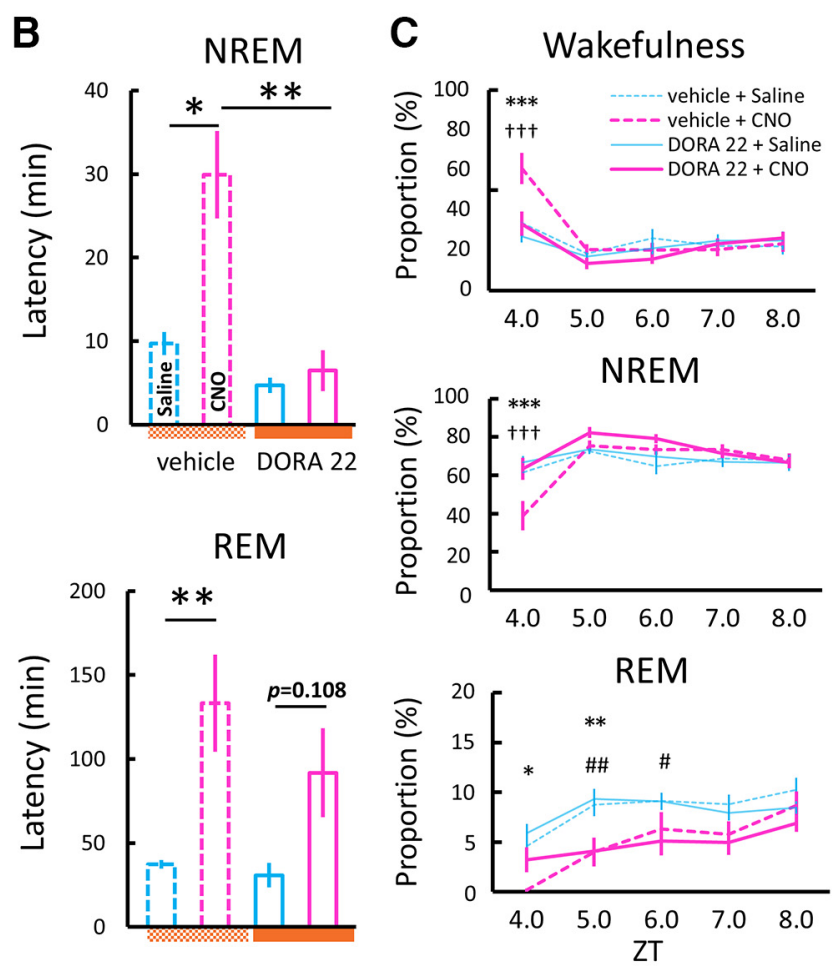

D

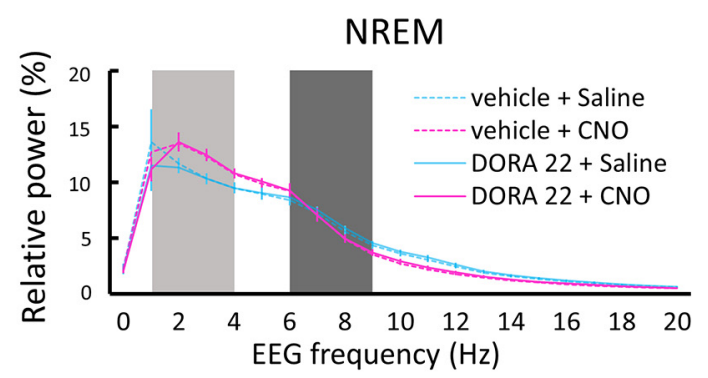

Figure 5. Dual orexin receptor antagonist (DORA-22) attenuated arousal effects induced by chemogenetic activation of GABA ${ }^{\mathrm{BNST}}$ neurons. $A$, Schematic drawing of experimental procedures. Vehicle (20\% vitamin E TPGS) or DORA-22 (30 mg/kg in 20\% vitamin E TPGS) was administered orally $30 \mathrm{~min}$ before the start of EEG/EMG recording. Saline or CNO $(5.0 \mathrm{mg} / \mathrm{kg})$ was administered intraperitoneally and mice were subjected to EEG/EMG recording starting at ZT4.0. $B$, Latency to first NREM (top) or REM (bottom) sleep after saline (blue bar) or CNO (magenta bar) administration. Vehicle + saline, $n=9$; vehicle + CNO, $n=9$; DORA-22 + saline, $n=9 ;$ DORA-22 + CNO, $n=9 ;{ }^{*} p<0.05,{ }^{* *} p<0.01$, one-way repeated-measures ANOVA followed by Tukey's post hoc test. Values are mean \pm SEM. C, Time of each state (top, wakefulness; middle, NREM sleep; bottom, REM sleep) between ZT4.0 and ZT8.0 after saline (blue line) or CNO (magenta line) administration with drugs. Dashed lines and solid lines represent vehicle and DORA-22 groups, respectively. Vehicle + saline, $n=9$; vehicle + CNO, $n=$ 9; DORA-22 + saline, $n=9 ;$ DORA-22 + CNO,$n=9 ;{ }^{*} p<0.05,{ }^{* *} p<0.01,{ }^{* * *} p<0.001$, animals and humans have shown that regions in the limbic systems are active during REM sleep (Maquet et al., 1996; Nofzinger et al., 1997; Sastre et al., 2000). This might explain why further excitation of GABA ${ }^{\mathrm{BNST}}$ neurons did not trigger a transition of wakefulness: because these neurons might be already active during REM sleep.

\section{Multiple pathways are involved in regulation of wakefulness by GABA ${ }^{\text {BNST }}$ neurons}

This study focused on the major neuronal type in the BNST, GAD67-expressing neurons (i.e., GABAergic neurons) (Bota et al., 2012; Kudo et al., 2012; Lebow and Chen, 2016). Previous studies have suggested that orexin neurons receive direct synaptic input from BNST neurons (González et al., 2016) and GABA ${ }^{\text {BNST }}$ neurons evoke IPSCs directly to orexin neurons (Jennings et al., 2013). However, it is not likely that $\mathrm{GABA}^{\mathrm{BNST}}$ neurons activate orexin neurons through direct synaptic contact with GABA as a neuromodulator (Li et al., 2002; Yamanaka et al., 2003; Xie et al., 2006). A population of GABA ${ }^{\text {BNST }}$ neurons also contains corticotropic releasing hormone (CRH) (Day et al., 1999; Nguyen et al., 2016), which activates orexin neurons (Winsky-Sommerer et al., 2004). These observations suggest the possibility that GABA ${ }^{\text {BNST }}$ neurons trigger the transition from NREM sleep to wakefulness through a neuronal pathway other than the orexin system and that these cells also more slowly activate orexin neurons through releasing CRH to sustain wakefulness. Alternatively, other indirect influences after excitation of GABA ${ }^{\text {BNST }}$ neurons might activate orexin neurons after prolonged excitation of these cells. Because orexin neurons receive abundant direct synaptic input by GABAergic neurons in the preoptic area (Saito et al., 2013), projection of GABA ${ }^{\text {BNST }}$ neurons to MPOA (Fig. $2 B$, Table 1) is a possible pathway to disinhibit orexin neurons. Alternatively, GABAergic interneurons in the LHA might play a role in the disinhibition of orexin neurons by GABA ${ }^{\text {BNST }}$ neurons. The circuit for the immediate arousal caused by acute optogenetic stimulation of GABA ${ }^{\text {BNST }}$ neurons is likely to be different from the circuitry involving orexinergic activation for prolonged wakefulness because DORA did not affect the transition (Fig. 1H). Because we found that GABA ${ }^{\text {BNST }}$ neurons send axonal projections to various brain regions that have been implicated in arousal regulations such as DpMe, PBN, and PAG (Fig. 2B), the rapid transition might be due to GABAergic signaling on these regions.

We also found that DREADD stimulation of GABA ${ }^{\text {BNST }}$ neurons was accompanied by an increase of c-Fos expression in TH-positive noradrenergic neurons in the LC but not in HDCpositive histaminergic neurons in the TMN and TPH-positive serotonergic neurons in the DR. This suggests that activation of noradrenergic neurons might be at least responsible for arousal induced by GABA ${ }^{\text {BNST }}$ stimulation.

This study showed that GABA ${ }^{\text {BNST }}$ neurons trigger the transition from NREM sleep to wakefulness without the function of the orexin system, but prolonged excitation of these neurons mobilizes orexin neurons to sustain arousal. This is consistent

vehicle + saline versus vehicle $+\mathrm{CNO}{ }^{\mathrm{ttt}} p<0.001$, vehicle + CNO versus DORA- $22+\mathrm{CNO}$ ${ }^{\#} p<0.05,{ }^{\# \#} p<0.01$, DORA-22 + saline versus DORA-22 + CN0; two-way repeatedmeasures ANOVA followed by Tukey's post hoc test. Values are mean \pm SEM. D, EEG power density shown as the mean percentage of total EEG power \pm SEM in each group for $2 \mathrm{~h}$ after injection for $1 \mathrm{~Hz}$ frequency bins between 0 and $20 \mathrm{~Hz}$. The delta $(1-4 \mathrm{~Hz}$, light dark) and theta $(6-9 \mathrm{~Hz}$, dark) ranges are indicated by shaded areas. No statistically significant differences were observed between groups $\left(n=9, F_{(3,24)}=0.46, p=0.71\right.$, two-way repeated-measures ANOVA). 
with the fact that orexin-deficient narcoleptic animals and humans can readily wake up by various external stimuli, but cannot sustain wakefulness (Sakurai, 2014). This is also consistent with previous observations in nonhuman primates showing that, although DORA promotes sleep, it protects the ability of selective arousal to emotionally salient stimuli, unlike the sedative hypnotic effects of benzodiazepines (Tannenbaum et al., 2016). This study also revealed that some GABAergic neurons play a role in increasing arousal, providing an important insight for considering the action of sleep-inducing agents because most of them are GABAergic modulators.

\section{References}

Anaclet C, Pedersen NP, Ferrari LL, Venner A, Bass CE, Arrigoni E, Fuller PM (2015) Basal forebrain control of wakefulness and cortical rhythms. Nat Commun 6:8744. CrossRef Medline

Armbruster BN, Li X, Pausch MH, Herlitze S, Roth BL (2007) Evolving the lock to fit the key to create a family of $\mathrm{G}$ protein-coupled receptors potently activated by an inert ligand. Proc Natl Acad Sci U S A 104:51635168. CrossRef Medline

Bota M, Sporns O, Swanson LW (2012) Neuroinformatics analysis of molecular expression patterns and neuron populations in gray matter regions: the rat BST as a rich exemplar. Brain Res 1450:174-193. CrossRef Medline

Cano G, Mochizuki T, Saper CB (2008) Neural circuitry of stress-induced insomnia in rats. J Neurosci 28:10167-10184. CrossRef Medline

Davis M, Walker DL, Miles L, Grillon C (2010) Phasic vs sustained fear in rats and humans: role of the extended amygdala in fear vs anxiety. Neuropsychopharmacology 35:105-135. CrossRef Medline

Day HE, Curran EJ, Watson SJ Jr, Akil H (1999) Distinct neurochemical populations in the rat central nucleus of the amygdala and bed nucleus of the stria terminalis: evidence for their selective activation by interleukin$1 \beta$. J Comp Neurol 413:113-128. Medline

Dong HW, Swanson LW (2003) Projections from the rhomboid nucleus of the bed nuclei of the stria terminalis: implications for cerebral hemisphere regulation of ingestive behaviors. J Comp Neurol 463:434-472. CrossRef Medline

Dong HW, Swanson LW (2004) Organization of axonal projections from the anterolateral area of the bed nuclei of the stria terminalis. J Comp Neurol 468:277-298. CrossRef Medline

Dong HW, Swanson LW (2006a) Projections from bed nuclei of the stria terminalis, magnocellular nucleus: implications for cerebral hemisphere regulation of micturition, defecation, and penile erection. J Comp Neurol 494:108-141. CrossRef Medline

Dong HW, Swanson LW (2006b) Projections from bed nuclei of the stria terminalis, dorsomedial nucleus: implications for cerebral hemisphere integration of neuroendocrine, autonomic, and drinking responses. J Comp Neurol 494:75-107. CrossRef Medline

Dong HW, Swanson LW (2006c) Projections from bed nuclei of the stria terminalis, anteromedial area: cerebral hemisphere integration of neuroendocrine, autonomic, and behavioral aspects of energy balance. J Comp Neurol 494:142-178. CrossRef Medline

Dong HW, Petrovich GD, Watts AG, Swanson LW (2001) Basic organization of projections from the oval and fusiform nuclei of the bed nuclei of the stria terminalis in adult rat brain. J Comp Neurol 436:430-455. CrossRef Medline

Fendt M, Endres T, Apfelbach R (2003) Temporary inactivation of the bed nucleus of the stria terminalis but not of the amygdala blocks freezing induced by trimethylthiazoline, a component of fox feces. J Neurosci 23:23-28. Medline

González JA, Iordanidou P, Strom M, Adamantidis A, Burdakov D (2016) Awake dynamics and brain-wide direct inputs of hypothalamic $\mathrm{MCH}$ and orexin networks. Nat Commun 7:11395. CrossRef Medline

Gotter AL, Winrow CJ, Brunner J, Garson SL, Fox SV, Binns J, Harrell CM, Cui D, Yee KL, Stiteler M, Stevens J, Savitz A, Tannenbaum PL, Tye SJ, McDonald T, Yao L, Kuduk SD, Uslaner J, Coleman PJ, Renger JJ (2013) The duration of sleep promoting efficacy by dual orexin receptor antagonists is dependent upon receptor occupancy threshold. BMC Neurosci 14:90. CrossRef Medline

Hayashi Y, Kashiwagi M, Yasuda K, Ando R, Kanuka M, Sakai K, Itohara S (2015) Cells of a common developmental origin regulate REM/non-
REM sleep and wakefulness in mice. Science 350:957-961. CrossRef Medline

Jennings JH, Rizzi G, Stamatakis AM, Ung RL, Stuber GD (2013) The inhibitory circuit architecture of the lateral hypothalamus orchestrates feeding. Science 341:1517-1521. CrossRef Medline

Kalin NH, Shelton SE, Fox AS, Oakes TR, Davidson RJ (2005) Brain regions associated with the expression and contextual regulation of anxiety in primates. Biol Psychiatry 58:796-804. CrossRef Medline

Khazaie H, Ghadami MR, Masoudi M (2016) Sleep disturbances in veterans with chronic war-induced PTSD. J Inj Violence Res 8:99-107. CrossRef Medline

Kim T, Thankachan S, McKenna JT, McNally JM, Yang C, Choi JH, Chen L, Kocsis B, Deisseroth K, Strecker RE, Basheer R, Brown RE, McCarley RW (2015) Cortically projecting basal forebrain parvalbumin neurons regulate cortical gamma band oscillations. Proc Natl Acad Sci U S A 112:35353540. CrossRef Medline

Kudo T, Uchigashima M, Miyazaki T, Konno K, Yamasaki M, Yanagawa Y, Minami M, Watanabe M (2012) Three types of neurochemical projection from the bed nucleus of the stria terminalis to the ventral tegmental area in adult mice. J Neurosci 32:18035-18046. CrossRef Medline

Lebow MA, Chen A (2016) Overshadowed by the amygdala: the bed nucleus of the stria terminalis emerges as key to psychiatric disorders. Mol Psychiatry 21:450-463. CrossRef Medline

Li Y, Gao XB, Sakurai T, van den Pol AN (2002) Hypocretin/orexin excites hypocretin neurons via a local glutamate neuron-a potential mechanism for orchestrating the hypothalamic arousal system. Neuron 36:11691181. CrossRef Medline

Maquet P, Péters J, Aerts J, Delfiore G, Degueldre C, Luxen A, Franck G (1996) Functional neuroanatomy of human rapid-eye-movement sleep and dreaming. Nature 383:163-166. CrossRef Medline

Mazzone CM, Pati D, Michaelides M, DiBerto J, Fox JH, Tipton G, Anderson C, Duffy K, McKlveen JM, Hardaway JA, Magness ST, Falls WA, Hammack SE, McElligott ZA, Hurd YL, Kash TL (epub ahead of print December 13, 2016) Acute engagement of Gq-mediated signaling in the bed nucleus of the stria terminalis induces anxiety-like behavior. Mol Psychiatry. CrossRef Medline

Mieda M, Hasegawa E, Kisanuki YY, Sinton CM, Yanagisawa M, Sakurai T (2011) Differential roles of orexin receptor-1 and -2 in the regulation of non-REM and REM sleep. J Neurosci 31:6518-6526. CrossRef Medline

Mieda M, Ono D, Hasegawa E, Okamoto H, Honma K, Honma S, Sakurai T (2015) Cellular clocks in AVP neurons of the SCN are critical for interneuronal coupling regulating circadian behavior rhythm. Neuron 85 : 1103-1116. CrossRef Medline

Nguyen AQ, Dela Cruz JA, Sun Y, Holmes TC, Xu X (2016) Genetic cell targeting uncovers specific neuronal types and distinct subregions in the bed nucleus of the stria terminalis. J Comp Neurol 524:2379-2399. CrossRef Medline

Nofzinger EA, Mintun MA, Wiseman M, Kupfer DJ, Moore RY (1997) Forebrain activation in REM sleep: an FDG PET study. Brain Res 770: 192-201. CrossRef Medline

Radulovacki M, Virus RM, Djuricic-Nedelson M, Green RD (1984) Adenosine analogs and sleep in rats. J Pharmacol Exp Ther 228:268274. Medline

Roth BL (2016) DREADDs for neuroscientists. Neuron 89:683-694. CrossRef Medline

Saito YC, Tsujino N, Hasegawa E, Akashi K, Abe M, Mieda M, Sakimura K, Sakurai $\mathrm{T}$ (2013) GABAergic neurons in the preoptic area send direct inhibitory projections to orexin neurons. Front Neural Circuits 7:192. CrossRef Medline

Sakurai T (2007) The neural circuit of orexin (hypocretin): maintaining sleep and wakefulness. Nat Rev Neurosci 8:171-181. Medline

Sakurai T (2014) The role of orexin in motivated behaviours. Nat Rev Neurosci 15:719-731. CrossRef Medline

Sakurai T, Nagata R, Yamanaka A, Kawamura H, Tsujino N, Muraki Y, Kageyama H, Kunita S, Takahashi S, Goto K, Koyama Y, Shioda S, Yanagisawa M (2005) Input of orexin/hypocretin neurons revealed by a genetically encoded tracer in mice. Neuron 46:297-308. CrossRef Medline

Saper CB, Fuller PM, Pedersen NP, Lu J, Scammell TE (2010) Sleep state switching. Neuron 68:1023-1042. CrossRef Medline

Sasaki K, Suzuki M, Mieda M, Tsujino N, Roth B, Sakurai T (2011) Pharmacogenetic modulation of orexin neurons alters sleep/wakefulness states in mice. PLoS One 6:e20360. CrossRef Medline 
Sastre JP, Buda C, Lin JS, Jouvet M (2000) Differential c-fos expression in the rhinencephalon and striatum after enhanced sleep-wake states in the cat. Eur J Neurosci 12:1397-1410. CrossRef Medline

Straube T, Mentzel HJ, Miltner WH (2007) Waiting for spiders: Brain activation during anticipatory anxiety in spider phobics. Neuroimage 37 : 1427-1436. CrossRef Medline

Sullivan GM, Apergis J, Bush DE, Johnson LR, Hou M, Ledoux JE (2004) Lesions in the bed nucleus of the stria terminalis disrupt corticosterone and freezing responses elicited by a contextual but not by a specific cueconditioned fear stimulus. Neuroscience 128:7-14. CrossRef Medline

Tannenbaum PL, Tye SJ, Stevens J, Gotter AL, Fox SV, Savitz AT, Coleman PJ, Uslaner JM, Kuduk SD, Hargreaves R, Winrow CJ, Renger JJ (2016) Inhibition of orexin signaling promotes sleep yet preserves salient arousability in monkeys. Sleep 39:603-612. CrossRef Medline

Ubaldi M, Giordano A, Severi I, Li H, Kallupi M, de Guglielmo G, Ruggeri B, Stopponi S, Ciccocioppo R, Cannella N (2016) Activation of hypocretin-1/ orexin-a neurons projecting to the bed nucleus of the stria terminalis and paraventricular nucleus is critical for reinstatement of alcohol seeking by neuropeptide S. Biol Psychiatry 79:452-462. CrossRef Medline

Van Dort CJ, Zachs DP, Kenny JD, Zheng S, Goldblum RR, Gelwan NA, Ramos DM, Nolan MA, Wang K, Weng FJ, Lin Y, Wilson MA, Brown EN (2015) Optogenetic activation of cholinergic neurons in the PPT or LDT induces REM sleep. Proc Natl Acad Sci U S A 112:584-589. CrossRef Medline

Winsky-Sommerer R, Yamanaka A, Diano S, Borok E, Roberts AJ, Sakurai T, Kilduff TS, Horvath TL, de Lecea L (2004) Interaction between the corticotropin- releasing factor system and hypocretins (orexins): a novel circuit mediating stress response. J Neurosci 24:11439-11448. CrossRef Medline

Wu S, Esumi S, Watanabe K, Chen J, Nakamura KC, Nakamura K, Kometani K, Minato N, Yanagawa Y, Akashi K, Sakimura K, Kaneko T, Tamamaki N (2011) Tangential migration and proliferation of intermediate progenitors of GABAergic neurons in the mouse telencephalon. Development 138:2499-2509. CrossRef Medline

Xie X, Crowder TL, Yamanaka A, Morairty SR, Lewinter RD, Sakurai T, Kilduff TS (2006) GABAB receptor-mediated modulation of hypocretin/orexin neurones in mouse hypothalamus. J Physiol 574:399-414. CrossRef Medline

Xiu J, Zhang Q, Zhou T, Zhou TT, Chen Y, Hu H (2014) Visualizing an emotional valence map in the limbic forebrain by TAI-FISH. Nat Neurosci 17:1552-1559. CrossRef Medline

Xu M, Chung S, Zhang S, Zhong P, Ma C, Chang WC, Weissbourd B, Sakai N, Luo L, Nishino S, Dan Y (2015) Basal forebrain circuit for sleep-wake control. Nat Neurosci 18:1641-1647. CrossRef Medline

Yamanaka A, Beuckmann CT, Willie JT, Hara J, Tsujino N, Mieda M, Tominaga M, Yagami Ki, Sugiyama F, Goto K, Yanagisawa M, Sakurai T (2003) Hypothalamic orexin neurons regulate arousal according to energy balance in mice. Neuron 38:701-713. CrossRef Medline

Zhang W, Zhang N, Sakurai T, Kuwaki T (2009) Orexin neurons in the hypothalamus mediate cardiorespiratory responses induced by disinhibition of the amygdala and bed nucleus of the stria terminalis. Brain Res 1262:25-37. CrossRef Medline 